\title{
Effect of phosphorus supply on root traits of two Brassica oleracea L. genotypes
}

Paula Pongrac ${ }^{1,2^{*}}$ (D), Hiram Castillo-Michel ${ }^{3}$, Juan Reyes-Herrera ${ }^{3}$, Robert D. Hancock ${ }^{4}$, Sina Fischer ${ }^{5}$, Mitja Kelemen ${ }^{2,6}$, Jacqueline A. Thompson ${ }^{1}$, Gladys Wright ${ }^{1}$, Matevž Likar ${ }^{7}$, Martin R. Broadley ${ }^{8}$, Primož Vavpetič̌ , Primož Pelicon ${ }^{2}$ and Philip J. White ${ }^{1,9,10}$

\begin{abstract}
Background: Phosphorus (P) deficiency limits crop production worldwide. Crops differ in their ability to acquire and utilise the P available. The aim of this study was to determine root traits (root exudates, root system architecture $(\mathrm{RSA})$, tissue-specific allocation of $\mathrm{P}$, and gene expression in roots) that (a) play a role in P-use efficiency and (b) contribute to large shoot zinc (Zn) concentration in Brassica oleracea.

Results: Two B. oleracea accessions (var. sabellica C6, a kale, and var. italica F103, a broccoli) were grown in a hydroponic system or in a high-throughput-root phenotyping (HTRP) system where they received Low $P(0.025 \mathrm{mM})$ or High P (0.25 mM) supply for 2 weeks. In hydroponics, root and shoot P and Zn concentrations were measured, root exudates were profiled using both Fourier-Transform-Infrared spectroscopy and gas-chromatography-mass spectrometry and previously published RNAseq data from roots was re-examined. In HTRP experiments, RSA (main and lateral root number and lateral root length) was assessed and the tissue-specific distribution of $\mathrm{P}$ was determined using micro-particle-induced-X-ray emission. The $\mathrm{C} 6$ accession had greater root and shoot biomass than the F103 accession, but the latter had a larger shoot P concentration than the C6 accession, regardless of the P supply in the hydroponic system. The F103 accession had a larger shoot Zn concentration than the C6 accession in the High P treatment. Although the F103 accession had a larger number of lateral roots, which were also longer than in the C6 accession, the C6 accession released a larger quantity and number of polar compounds than the F103 accession. A larger number of P-responsive genes were found in the Low $P$ treatment in roots of the F103 accession than in roots of the C 6 accession. Expression of genes linked with "phosphate starvation" was upregulated, while those linked with iron homeostasis were down-regulated in the Low $P$ treatment.
\end{abstract}

Conclusions: The results illustrate large within-species variability in root acclimatory responses to $P$ supply in the composition of root exudates, RSA and gene expression, but not in P distribution in root cross sections, enabling P sufficiency in the two B. oleracea accessions studied.

Keywords: Phosphorus use efficiency, Phosphorus deficiency, Root exudates, Spatial distribution of phosphorus, Kale, Broccoli, RNAseq, Gene expression

\footnotetext{
* Correspondence: paula.pongrac@gmail.com

${ }^{1}$ Ecological Science Group, The James Hutton Institute, Invergowrie, Dundee DD2 5DA, UK

2Jožef Stefan Institute, Jamova 39, SI-1000 Ljubljana, Slovenia

Full list of author information is available at the end of the article
}

(c) The Author(s). 2020 Open Access This article is licensed under a Creative Commons Attribution 4.0 International License, which permits use, sharing, adaptation, distribution and reproduction in any medium or format, as long as you give appropriate credit to the original author(s) and the source, provide a link to the Creative Commons licence, and indicate if changes were made. The images or other third party material in this article are included in the article's Creative Commons licence, unless indicated otherwise in a credit line to the material. If material is not included in the article's Creative Commons licence and your intended use is not permitted by statutory regulation or exceeds the permitted use, you will need to obtain permission directly from the copyright holder. To view a copy of this licence, visit http://creativecommons.org/licenses/by/4.0/ The Creative Commons Public Domain Dedication waiver (http://creativecommons.org/publicdomain/zero/1.0/) applies to the data made available in this article, unless otherwise stated in a credit line to the data. 


\section{Background}

In plants, phosphorus $(\mathrm{P})$ is involved in cellular bioenergetics and metabolic regulation, and is an important structural component of essential biomolecules including DNA, RNA, phospholipids, ATP and sugarphosphates $[1,2]$. When $\mathrm{P}$ is in limited supply plants utilise a multifaceted set of morphological, biochemical and molecular strategies to increase the availability of $\mathrm{P}$ in the soil, adjust root growth to access P-rich soil patches and / or modify the ways in which $\mathrm{P}$ is used internally (improving P-acquisition, P-reallocation and Premobilisation within the plant) [1, 3-5].

The initial biochemical and morphological adjustments made by plants to increase the acquisition of $\mathrm{P}$ occur in roots. Such changes have been described in detail for various crops. They include traits that increase: (a) the solubilisation of inorganic $\mathrm{P}$ and the breakdown of organic $\mathrm{P}$ compounds in the soil, (b) the volume of soil explored by roots or the root surface area available to capture soluble P, (c) the rate of $\mathrm{P}$ uptake across the plasma membrane of root cells, and (d) whole-plant traits that affect root growth and nutrient capture $[6,7]$. "Topsoil foraging" is believed to be the most efficient root ideotype for $\mathrm{P}$ acquisition $[5,8]$ presuming that $\mathrm{P}$ is concentrated in the top layers of the soil. The most favourable root system architecture (RSA) for $\mathrm{P}$ acquisition is a combination of $\mathrm{i}$ ) large root biomass, root / shoot biomass ratio, cortical aerenchyma, root surface area in the topsoil and in patches of high $P$ phytoavailability, ii) ability to form mycorrhizal symbioses, acidify the rhizosphere, release organic compounds and phosphatases, and iii) greater phosphate $\left(\mathrm{P}_{\mathrm{i}}\right)$ uptake capacity of root cells $[5,8]$. In this context, a greater number of lateral roots was found in Brassica oleracea L. accessions with average to high yields at suboptimal $\mathrm{P}$ supply and the number of lateral roots increased with yield potential [9]. Furthermore, total lateral root length and lateral root growth rate were larger for accessions that had greater yields at small and large P supply, while root angle did not appear to be related to greater yields [9]. Similar adaptations have been observed for other crops, e.g. soybean (Glycine max (L.) Merr.) [10] and oilseed rape (Brassica napus L.) [11]. In Arabidopsis thaliana (L.) Heynh., low P availability promotes the development of a highly branched root system to the detriment of the primary root, characterised by greater production of lateral roots and root hairs $[12,13]$.

The alteration of root architecture (i.e. the spatial configuration of a root system) is a powerful vehicle for the development of crop plants with efficient $\mathrm{P}_{\mathrm{i}}$ acquisition $[7,14,15]$. Nevertheless, root exudates (i.e. organic metabolites and inorganic species released by the roots to their surroundings) play a complementary role in the mobilisation of sparingly soluble mineral elements in the rhizosphere [16]. Root exudation has been shown to be influenced strongly by the nutritional status of the plant and both the quantity and the composition of exudates differ depending on the particular nutrient ( $\mathrm{P}, \mathrm{Fe}, \mathrm{K}$ or $\mathrm{N})$ deficiency [17]. Efficient soybean genotypes, for example, respond to low $\mathrm{P}$ availability by exuding a greater quantity of organic compounds into the rhizosphere, which increases $\mathrm{P}$ availability and results in the crop meeting $\mathrm{P}$ requirements, producing consistent biomass and seed yield with reduced fertiliser addition [18]. Furthermore, the (bio) availability of $\mathrm{P}_{\mathrm{i}}$ can affect the overall profile of the root exudates [19]. In P-deficient strawberry (Fragaria $\times$ ananassa cv. Elsanta) plants, for example, the concentrations of citric acid, galactaric acid, malic acid, lysine, proline, and sorbitol6-phosphate in root exudates were larger in P-deficient plants than in P-replete plants [20].

Phosphorus-deficiency in plants can also affect the uptake of other essential and non-essential mineral elements $[19,21]$. In particular, $P$ deficiency can induce zinc (Zn) over-accumulation [22-25]. This interaction has been attributed to (a) biochemical changes affecting cell membranes [26] and/or increased apoplastic uptake of $\mathrm{Zn}$ [27], (b) morphological changes in RSA that allow greater volumes of soil to be exploited for $\mathrm{Zn}$ acquisition [5], or (c) cross talk of molecular signalling networks, by which $P_{i}$ deficiency upregulates the expression of genes encoding $\mathrm{Zn}$ transporters [22, 28, 29]. Conversely, Pinduced $\mathrm{Zn}$ deficiency has been reported for some crops [30-34]. Since Zn deficiency in plants is linked with Zn malnutrition in animals, understanding $\mathrm{Zn}$ nutrition in plants in relation to environmental factors is an important subject [21, 23, 26, 35-37].

As in leaves [38], the cell-type specific distribution of elements in roots depends on the phylogenetic placement of the plant species and on the environment. Although $\mathrm{P}$ nutrition has been studied in a wide range of plant species, particularly in crops, studies of the tissue-specific distribution of $\mathrm{P}$ in roots are rare and typically a serendipitous result of using multi-element analytical techniques. In general, a progressive increase in cellular P from the rhizodermis towards the endodermis, where the majority of $\mathrm{P}$ is located, and smaller P concentrations in cells located within the stele has been reported [39-42].

The aim of this study was to determine root traits (root exudates, RSA, gene expression and tissue-specific allocation of $\mathrm{P}$ in roots) that (a) play a role in $\mathrm{P}$-use efficiency and (b) contribute to larger shoot $\mathrm{Zn}$ concentration using two contrasting B. oleracea accessions.

\section{Results}

\section{Hydroponic experiments}

Both B. oleracea accessions grew well at both Low $P$ and High $P$ supply (henceforth referred to as treatments) and showed no $\mathrm{P}_{\mathrm{i}}$ deficiency symptoms (Additional file 1: Fig. S1). There was no significant effect (Two-way ANOVA) of the treatments on the root lengths and root 
and shoot dry matter, but a statistically significant genotype effect was found (Additional file 2: Table S1), with the F103 accession having longer roots $(28.2 \pm 0.86 \mathrm{~cm})$ than the $\mathrm{C} 6$ accession $(25.6 \pm 0.88 \mathrm{~cm})$, and the $\mathrm{C} 6 \mathrm{ac}-$ cession having larger average root and shoot dry matter than the F103 accession (Fig. 1a, b).

There was a statistically significant effect of genotype and treatment on root and shoot $\mathrm{P}$ concentrations, $\mathrm{P}$ translocation factor (shoot $\mathrm{P} /$ root $\mathrm{P}$ concentration) and $P$ efficiency ratio (PER) (Additional file 2: Table S1). The largest root $\mathrm{P}$ concentrations were measured in plants receiving High $P$ supply, and the shoot $\mathrm{P}$ concentration of the F103 accession receiving a Low $P$ supply did not differ from the shoot $\mathrm{P}$ concentration of the $\mathrm{C} 6$ accession receiving a High $P$ supply (Fig. 1c, d). Phosphorus translocation factors were larger in the F103 accession than in the C6 accession in both treatments (Fig. 1e). The greatest PER was found in the C6 accession receiving a Low P supply and the smallest in the F103 accession receiving a High $P$ supply (Fig. 1f). The root, shoot and plant P contents
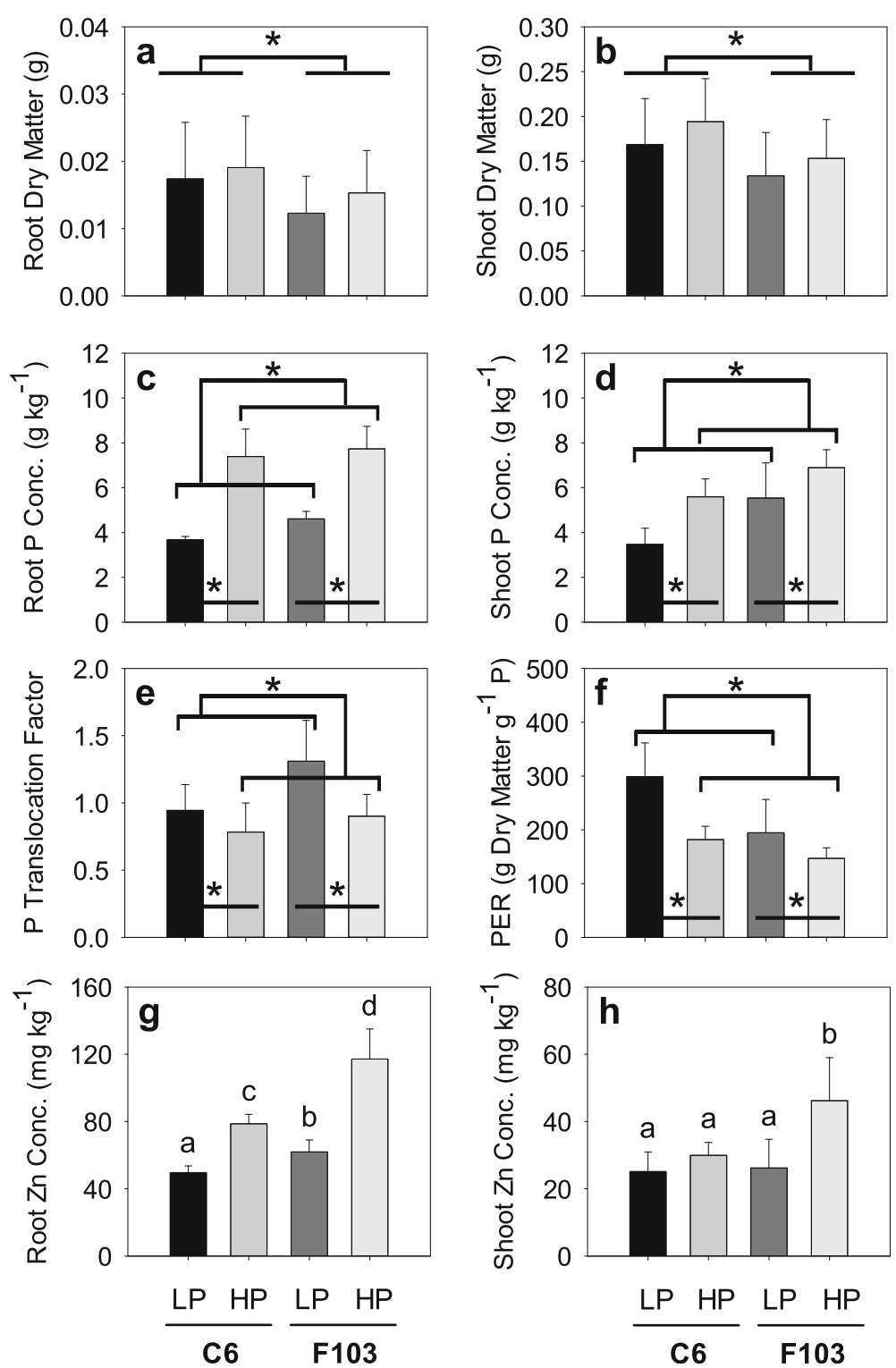

Fig. 1 Root and shoot dry matter $(\mathbf{a}, \mathbf{b})$, root and shoot phosphorus $(P)$ concentration in dry matter $(\mathbf{c}, \mathbf{d}), P$ translocation factor (shoot $P /$ root $P$; e), P efficiency ratio (PER; $\mathbf{f}$ ), a measure of $\mathrm{P}$ use efficiency calculated as Shoot Dry Matter/(Shoot P Concentration $\times$ Shoot Dry Matter), and root and shoot zinc (Zn) concentration in dry matter $(\mathbf{g}, \mathbf{h})$ of two Brassica oleracea accessions (C6 and F103) grown hydroponically for two weeks in solutions containing $0.025 \mathrm{mM} \mathrm{P}$ (Low P; LP) and $0.25 \mathrm{mM} \mathrm{P} \mathrm{(High} \mathrm{P;} \mathrm{HP).} \mathrm{Data} \mathrm{are} \mathrm{means} \mathrm{(} n=18$ for dry weight and $n=5-6$ for concentrations, translocation factor and PER) and standard errors. Asterisks and different letters indicate statistically significant differences (two-way analysis of variance followed by Holm-Sidak post hoc test at $P<0.05)$ 
were significantly larger in both accessions in the High $P$ supply than in the Low P supply (Additional file 1: Fig. S2).

There was a statistically significant effect of genotype, treatment and their interaction on both root and shoot $\mathrm{Zn}$ concentrations (Additional file 2: Table S1). The largest root and shoot $\mathrm{Zn}$ concentrations were measured in the F103 accession receiving a High $P$ supply (Fig. 1g, h). Zinc translocation factors did not differ between the two accessions but were larger in the Low $P$ supply (on average $0.49 \pm 0.12$ ) than in the High $P$ supply (on average $0.39 \pm 0.08$ ).

Two-way ANOVA of shoot and root S, K, Ca, Mn and Fe concentrations revealed that i) there were no significant effects of genotype, treatment or their interaction on shoot $\mathrm{Ca}, \mathrm{S}, \mathrm{K}, \mathrm{Mn}$ or Fe concentrations, ii) $\operatorname{root} \mathrm{Ca}$, $\mathrm{K}$ and $\mathrm{Mn}$ concentrations were affected by genotype, iii) High $P$ supply resulted in larger root $\mathrm{Ca}, \mathrm{S}, \mathrm{K}, \mathrm{Mn}$ and Fe concentrations than Low $P$ treatment, and iv) there were no genotype $\mathrm{x}$ treatment interactions on root $\mathrm{S}, \mathrm{K}$, $\mathrm{Ca}, \mathrm{Mn}$ or Fe concentrations (Fig. S3).

\section{Metabolome profiling of root exudates}

The comparison of the ATR-FTIR spectra of the root exudates revealed large differences between the accessions and the treatments (Fig. 2). In the characteristic range of the spectra (wavenumber $800-1700 \mathrm{~cm}^{-1}$ ) the functional group profiles of the two accessions differed clearly (Fig. 2a). Considering the whole characteristic range as the source of variation, the PCA showed separation of the two accessions, mainly in the principal component one (PC1), which explained $81 \%$ of the variation (Fig. 2b). In the principal component two (PC2), which explained $12 \%$ of the variation, strong separation between treatments was seen for the F103 accession only. Bands contributing distinctly to the separation in the
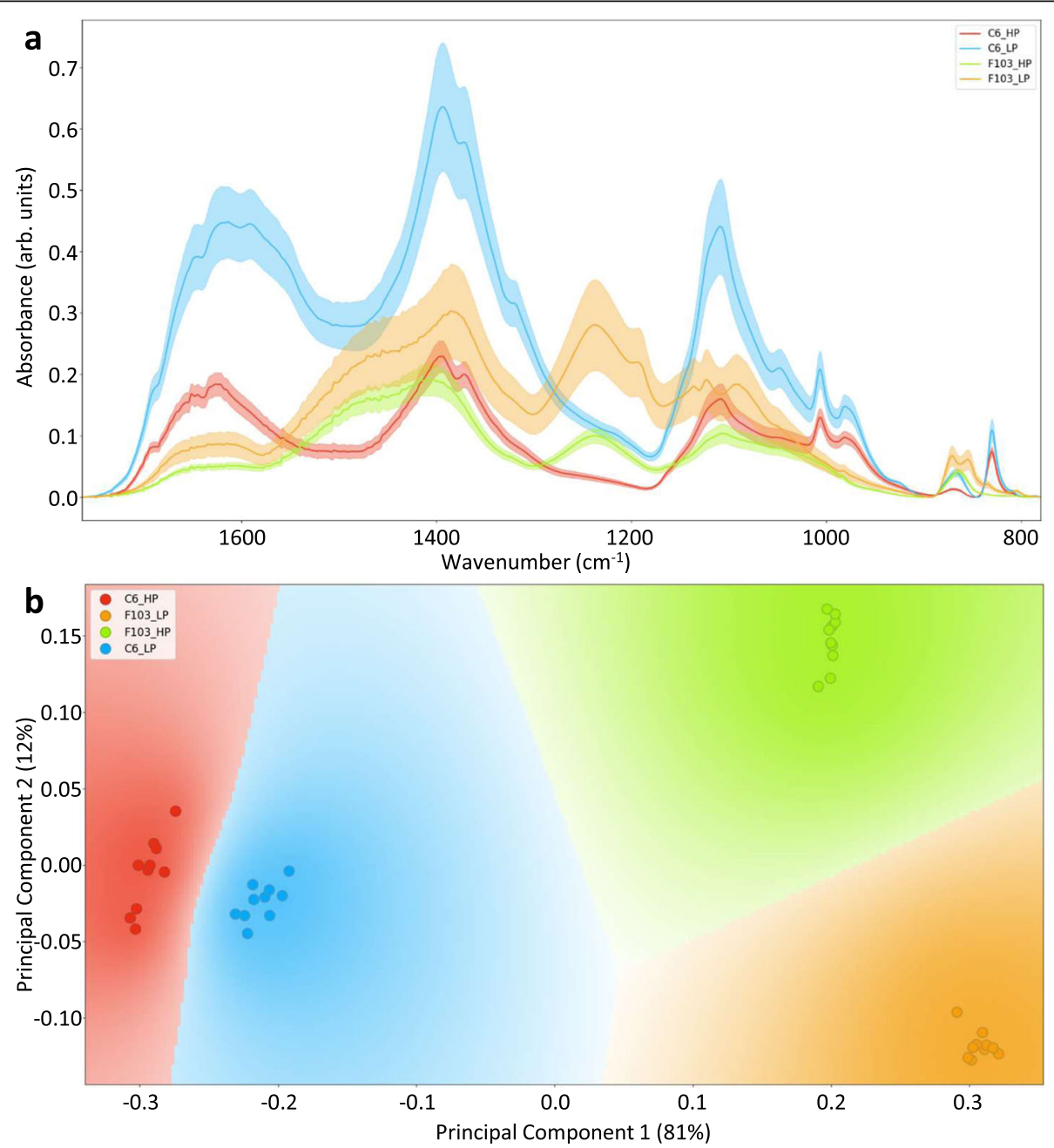

Fig. 2 Attenuated total reflection-Fourier transform infrared analysis of root exudates collected from two Brassica oleracea accessions (C6 and F103) grown hydroponically for two weeks in solutions containing $0.025 \mathrm{mM}$ phosphorus (P; Low P; LP) and $0.25 \mathrm{mM}$ P (High P; HP). Average spectra of ten measurements \pm standard deviation (a) and principal component analysis, which depicts the first two principal components for response variables grouped by treatments and accessions (b) 
dimension of $\mathrm{PC} 1$ and as such to the separation of the accessions were those between $\approx 1200-1300 \mathrm{~cm}^{-1}$, between $\approx 1400-1550 \mathrm{~cm}^{-1}$ and between $\approx 1620-1690$ $\mathrm{cm}^{-1}$ (Additional file 1: Fig. S4). Several other minor contributions were also apparent, e.g. $\approx 830 \mathrm{~cm}^{-1}, \approx 870$ $\mathrm{cm}^{-1}, \approx 890 \mathrm{~cm}^{-1}, \approx 970 \mathrm{~cm}^{-1}, \approx 1100 \mathrm{~cm}^{-1}, \approx 1110 \mathrm{~cm}^{-1}$, $\approx 1380 \mathrm{~cm}^{-1}$ and $\approx 1400 \mathrm{~cm}^{-1}$ (Additional file 1: Fig. S4). Because bands in ATR-FTIR spectra are a combination of symmetric and asymmetric stretching, bending and wagging vibrations of compounds present in the samples the attribution of a band at a certain wavelength to a particular compound is complicated [43, 44]. However, some general observations can be made in conjunction with published data ([45] and references therein). For example, bands between $\approx 1620-1690 \mathrm{~cm}^{-1}$ are mainly a result of vibrations from protein (amide I) and pectin, the bands between $\approx 1400-1550 \mathrm{~cm}^{-1}$ are mainly a result of vibrations of carboxyl groups from lignin, pectin, various polysaccharides and protein (amide II), while bands between $\approx 1120-1300 \mathrm{~cm}^{-1}$ are mainly a result of vibrations of lignin, proteins (amide III), nucleic acids and various polysaccharides [45]. Thus, it appears that the largest contributors to the separation of the two accessions were proteins. By contrast, bands contributing distinctly to the separation in the dimension of PC2 and as such to the separation of the Low $P$ and the High $P$ treatments in the F103 accession were those between $\approx 1560-1700 \mathrm{~cm}^{-1}$, between $\approx 1390-1560 \mathrm{~cm}^{-1}$, between $\approx 1120-1380 \mathrm{~cm}^{-1}$, between $\approx 960-1090 \mathrm{~cm}^{-1}$ and at $\approx 880 \mathrm{~cm}^{-1}$ and at $\approx 830 \mathrm{~cm}^{-1}$ (Additional file 1: Fig. S5). These contributing bands can be assigned to the vibrations of pectin and various polysaccharides (e.g. $\approx 1020$ $800 \mathrm{~cm}^{-1}, \approx 1155 \mathrm{~cm}^{-1}, \approx 1260-1300 \mathrm{~cm}^{-1}$ and $\approx 1370$ $\mathrm{cm}^{-1}, \approx 1400-1460 \mathrm{~cm}^{-1}$ [45], which implies that the largest differences in root exudates in plants of the F103 accession with Low P and High P supply may be due to the presence of polysaccharides.

Using GC-MS, a total of 39 polar compounds (organic acids, sugars, sugar alcohols, amino acids, lignins and others) were identified in root exudates of the C6 accession and 34 compounds in root exudates of the F103 accession (Additional file 2: Table S2). In all instances, the relative concentrations of metabolites were larger in root exudates of the $\mathrm{C} 6$ accession than the F103 accession. In root exudates from the C6 accession three compounds (oxalic acid, galactinol and dihydroxydihydrofuranone) were found to be more abundant in the High P treatment than in the Low P treatment with one compound (galactose) detected in the High $P$ treatment only and ten compounds (fumaric acid, fructose, sucrose, galactosyl glycerol, phenylalanine, oxoproline, tryptophan, ßalanine, proline and methionine) detected in the Low $P$ treatment only (Additional file 2: Table S2). The remaining 25 compounds were more abundant in the
Low $P$ treatment compared to the High $P$ treatment in root exudate from the $\mathrm{C} 6$ accession. By contrast, in root exudate from the F103 accession fourteen compounds were more abundant in the High $P$ treatment than the Low $P$ treatment and thirteen compounds were detected in the High $P$ treatment only and one compound (fumaric acid) was detected in the Low $P$ treatment only (Additional file 2: Table S2). The remaining six compounds were more abundant in root exudates from the Low $P$ treatment compared to the High $P$ treatment. $\log 2$ fold changes (comparing Low P with High P treatments) are shown in Fig. 3. The fold changes were calculated for the 30 compounds detected in both treatments. Significant changes in exudation ( $\log 2$ fold change $>2$ ) were found for eighteen compounds in the C6 accession and seven in the F103 accession.

\section{Root architecture}

There was an apparent difference in root system architecture (RSA) between the two accessions, particularly in the occurrence and the length of the lateral roots in the uppermost part of the main root (close to the shoot; representative photographs of RSA of the accessions grown in different treatments are shown in Fig. 4). For this reason, the number and length of lateral roots were determined in each of four equidistant parts along the main root axis (first, second, third and fourth quartiles were distinguished with the first quartile positioned at the top of the main root). The length of the main root was affected by treatment and not by genotype or the interaction between $\mathrm{P}$ treatments and genotype (Two-way ANOVA; Additional file 2: Table S3). The average main root length was $8.5 \mathrm{~cm}$ in the Low $P$ treatment and it increased to $9.6 \mathrm{~cm}$ in the High $P$ treatment. Data for lateral root length and lateral root number was not normally distributed, therefore ANOVA on Ranks was performed. The analysis revealed significant differences in lateral root lengths between the accessions in the Low $P$ treatment, but not in the High $P$ treatment. In addition, there was no statistically significant difference in the lateral root length between the two treatments for either the C6 or the F103 accession. The C6 accession had fewer lateral roots that were shorter than those of the F103 accession in the uppermost quartile. This trend was still seen in the second quartile, although the differences were not as large (Fig. 4). In the third quartile lateral roots were only occasionally found and their occurrence was not affected by any of the variables (Additional file 2: Table S3). In the fourth quartile lateral root emergence had not yet occurred and thus lateral roots were not visible.

\section{Distribution of phosphorus in the root cross sections}

Concentrations of elements in particular tissues differ along the length of plant roots [46-49]. To be able to 


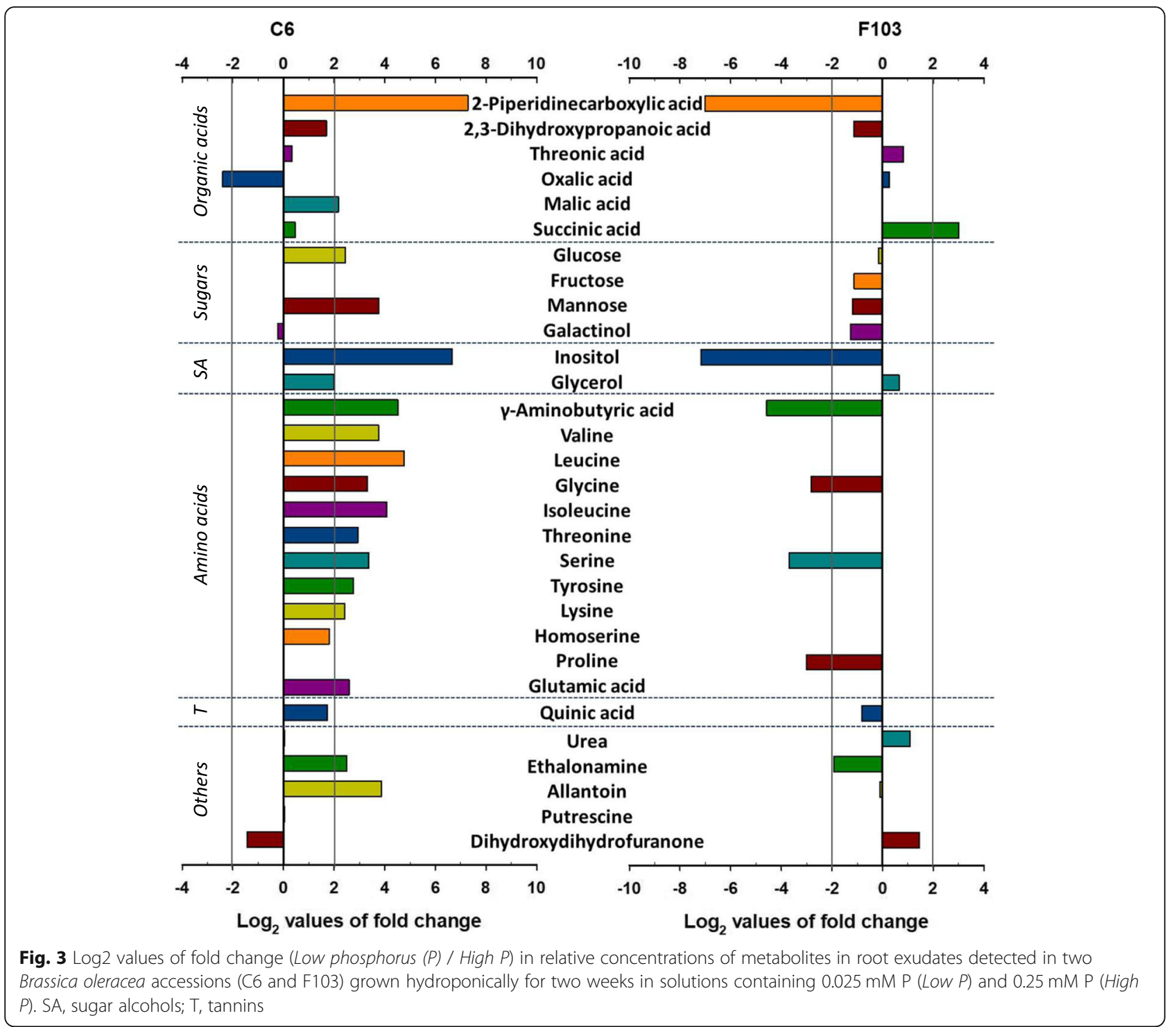

compare the distributions of $\mathrm{P}$ in the two treatments and the two accessions quantitatively, regions of the roots of similar developmental stage were examined. Because the shortest distance from the root tip and the first lateral root was determined to be at $2.6 \mathrm{~cm}$ in the F103 accession, all cross sections were taken between 2.0 and 2.5 $\mathrm{cm}$ above the root tip (the maturation zone). Resulting cross sections were on average $288 \pm 9 \mu \mathrm{m}$ in diameter. The root cross sections were larger in the C6 accession than in the F103 accession receiving Low P supply, while the opposite was observed in the High P supply (Fig. 5a).

Whole root-cross sections contained on average $6.30 \pm 0.90 \mathrm{~g} \mathrm{P} \mathrm{kg}^{-1}$ (Fig. 5b). The largest concentrations of $\mathrm{P}$ in root cross sections of both $B$. oleracea accessions were found in the endodermis (Fig. 5b), a layer of cells surrounding the vascular bundle. Although accession and treatment effects on the distribution of $\mathrm{P}$ within the root were not significant, some observations can be made. On average less $\mathrm{P}$ was measured in whole crosssections and in the endodermis of roots of the C6 accession receiving the Low $P$ treatment compared to the High $P$ treatment, whilst such trends were not observed for roots of the F103 accession (Fig. 5b). In the High P supply, the C6 accession had a larger P concentration in the endodermis than the F103 accession.

\section{Gene expression}

RNAseq data shown here originate from a previously published dataset [29] and were processes anew by concentrating on the different P supply (Low P and High P) only; differences in gene expression in response to Low $\mathrm{P}$ supply were assessed. In the C6 accession 178 genes were differentially regulated in Low $P$ supply in comparison to High P supply while in the F103 accession 320 


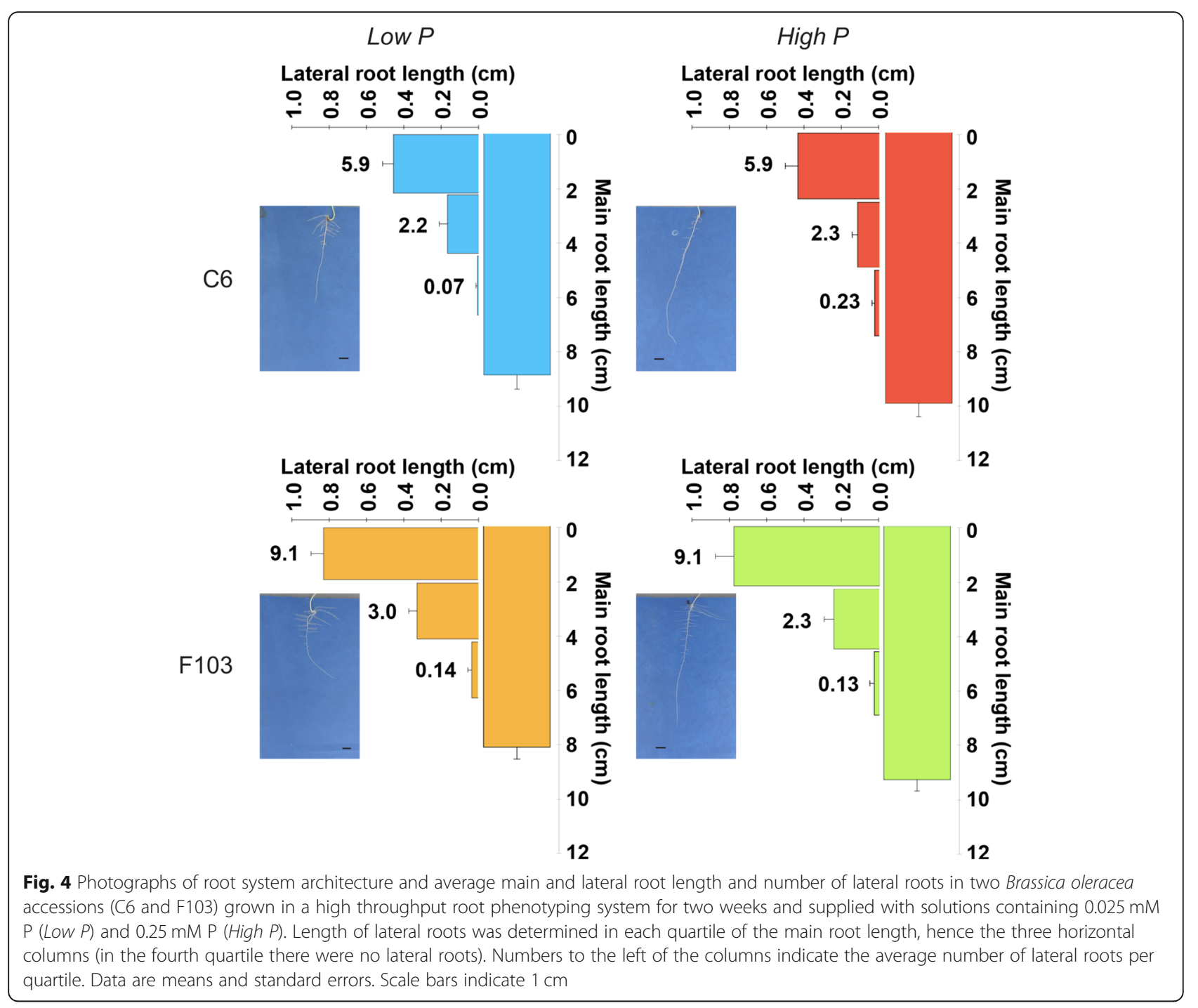

DEGs were detected (Fig. 6a). These DEGs (Additional file 2: Table S4) are referred to as P-responsive. The two accessions had 51 P-responsive DEGs in common, of which the majority (40) were up-regulated in the Low $P$ treatment. An example of these up-regulated DEGs is Bo9g181910, which is annotated as a phosphate starvation response gene. Only three DEGs were downregulated in both accessions as a response to Low $P$ supply. Among them the Bo5g008780 is annotated as the high affinity nitrate transporter 2.1. Eight DEGs showed contrasting responses to $P$ supply in the two accessions. Only one P-responsive gene linked with $\mathrm{Zn}$ transport was found (Bo1g021930) and was down-regulated in the C6 accession in the Low P treatment. We searched for over or underrepresented gene ontology (GO) terms among the P-responsive DEGs by comparing them statistically to the respective GO group size in all expressed B. oleracea genes (Fig. 6b). All GO enrichments can be found in Additional file 2: Table S5. We detected GO term enrichments for both accessions, but only rarely were these enrichments common to both accessions. One of the common enrichments in GO terms was "glycolipid biosynthetic process" suggesting that both accessions respond to Low $P$ supply by changing their lipid metabolism. A MapMan analysis of the gene expression changes, annotated with their $A$. thaliana orthologues, illustrates which cellular processes are affected schematically (Fig. 6c). The expression profiles of Presponsive DEGs (depicted as their orthologues in $A$. thaliana listed in the Additional file 2: Table S6), are shown in the line graphs below each group. Processes strongly impacted by $\mathrm{P}$ starvation include those influencing the regulation of transcription, RNA processing, protein synthesis and modification, responses to stress, redox activities, cell signalling, hormonal regulation, metal homeostasis and solute transport.

\section{Discussion}

As expected, when grown for 2 weeks in hydroponics the two selected $B$. oleracea accessions exhibited 

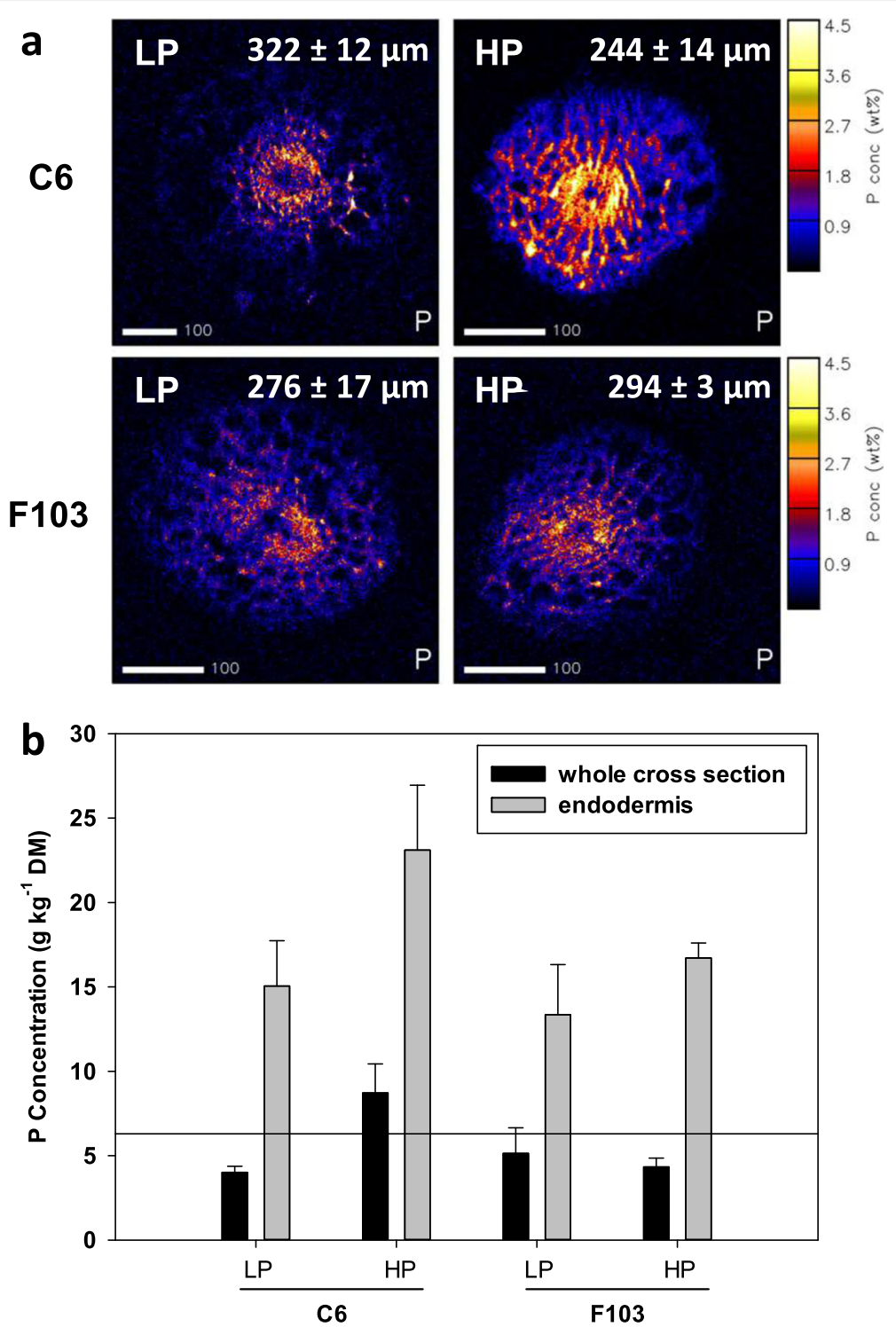

Fig. 5 Representative quantitative phosphorus (P) distribution maps in root cross sections of two Brassica oleracea accessions (C6 and F103; a) grown in a high throughput root phenotyping system for two weeks and supplied with solutions containing $0.025 \mathrm{mM} P$ (Low P; LP) and 0.25 mM P (High P; LP). Values in the top right corners of $\mathrm{P}$ distribution maps indicate mean diameter of root cross sections $(n=3-8)$. Average $\mathrm{P}$ concentration in dry matter of whole root cross sections and endodermis $(n=3-7 ; \mathrm{b})$. Reference line in panel $\mathrm{b}$ indicates average whole-cross section concentration $(n=18)$. Shown are means \pm standard errors

measurable ionomic (Fig. 1, Additional file 1: Figs. S2,3), metabolic (Figs. 2, 3), genetic (Fig. 6), and morphological (Figs. 4, 5) responses to reduced $\mathrm{P}$ availability. Both accessions up-regulated the expression of a gene associated with responses to P-deficiency (Bo9g181910), which suggests that the Low $P$ treatment caused sub-optimal plant $\mathrm{P}$ nutrition. However, the responses to reduced $\mathrm{P}$ availability occurred before visible deficiency symptoms in shoots were observed, such as a reduction in shoot growth (Fig. 1b) and the accumulation of purple anthocyanin pigmentation (Additional file 1: Fig. S1), which is indicative of systemic P deficiency [50]. In addition, in both accessions an adequate shoot $\mathrm{P}$ concentration was measured in plants receiving either a High $P$ or a Low $P$ supply (Fig. 1d). Nevertheless, the two accessions appeared to achieve P sufficiency [51] by employing different mechanisms. The C6 accession relied more on changes in the quantity and composition of root exudates, while the F103 accession relied more on an extensive root system which, surprisingly, did not depend on the $\mathrm{P}$ supply. These conclusions were based on the following observations i) in hydroponics (a) the $\mathrm{C} 6$ accession had larger biomass (Fig. 1b) but smaller shoot $\mathrm{P}$ (Fig. 1d) and Zn (Fig. 1h) concentrations, and larger 
a

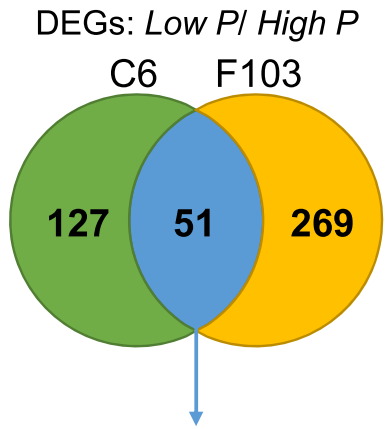

40: up-regulated in both accessions

3: down-regulated in both accessions

6: down-regulated in F103 and up-regulated in $\mathrm{C} 6$

2: up-regulated in F103 and down-regulated in $\mathrm{C} 6$

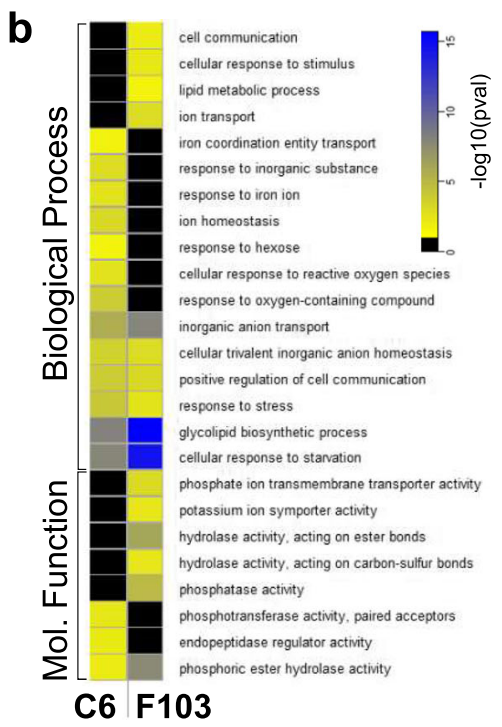

C C6 $\mathrm{F} 103$

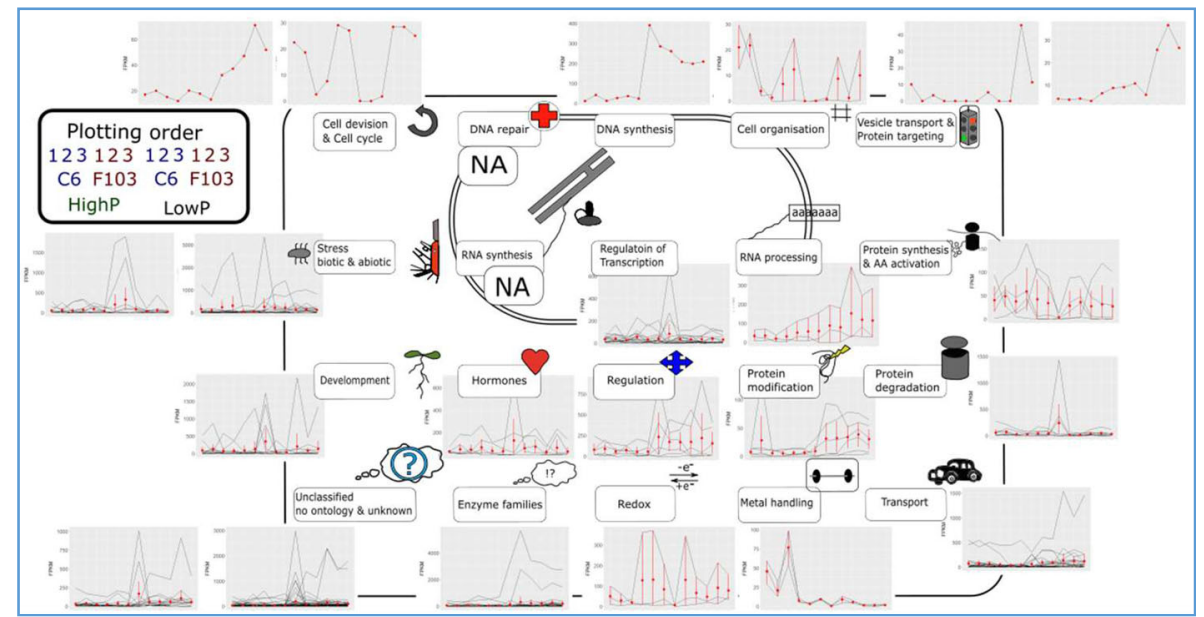

Fig. 6 Comparative analysis of differentially expressed genes (DEGs) in roots of two Brassica oleracea accessions (C6 and F103) grown hydroponically for two weeks in solutions containing $0.025 \mathrm{mM} \mathrm{P} \mathrm{(Low} \mathrm{P)} \mathrm{and} 0.25 \mathrm{mM}$ P (High P). Differentially expressed genes were defined by comparing the gene expression in the Low $P$ treatment with the gene expression in the High $P$ treatment for each of the $B$. oleracea accession. a Schematic representation of the common and accession-specific DEGs. $\mathbf{b}$ Gene ontology analysis of enriched functional categories of these DEGs. Depicted are $p$-values to highlight the significance of the over-representation of the corresponding functional category. Only child terms are displayed here. The full analysis can be found in Additional file 2: Table S6. c A MapMan analysis illustrating responses of functional pathways to the Low $P$ treatment. The image was designed after the MapMan output for cellular overview. Line graphs below categories show expression of respective genes in response to decreasing $P$ supply with the average and the confidence interval are shown in red. Arabidopsis thaliana orthologues of $B$. oleracea P-responsive DEGs were used as input together with expression values detected in the two B. oleracea accessions

PER, a measure of P-use efficiency [9], especially when receiving Low $P$ supply, than the F103 accession (Fig. 1f), (b) the C6 accession exuded a larger number of polar compounds and their relative concentrations were larger than in the F103 accession (Fig. 3 and Additional file 2: Table S2), and (c) roots of the C6 accession had fewer DEGs than roots of the F103 accession, and ii) in the HTRP experiment, the F103 accession had a larger number of lateral roots, which were longer than in the C6 accession (Fig. 4). It appears that in the F103 accession growing roots was more energy demanding than was the root exudation in the C6 accessions, in agreement with recent estimates [16, 52].
Root exudates are employed by many plants to release bioavailable nutrients from the soil and to interact with rhizosphere microbiota and herbivores [17, 53, 54]. Their mode of action, in relation to plant nutrition, can include direct effects on nutrient solubility, as exemplified by the effects of organic acids released into the rhizosphere, or indirect effects, such as the attraction of rhizosphere microorganisms that increase the bioavailability of nutrients in the soil [17]. Although the quantity and the composition of root exudates have been shown to be species and genotype-specific $[55,56]$, the differences in the root exudate composition between the two 
B. oleracea accessions studied here, captured by ATRFTIR (Fig. 2), was still remarkable. These differences were apparent despite potential issues $[57,58]$ with the length of root exudate collection, which exceeded the proposed optimal time for washing [59]. Since both accessions were exposed to the same procedure, the differences observed in their root exudate composition and its response to $\mathrm{P}$ supply can be attributed to genotypic and treatment effects. The significant response to the Low $P$ supply observed in the C6 accession, suggests a strong interaction between root exudates and P-stress in this accession. Proteins appeared to contribute most prominently to the differences in exudates between the two accessions. Indeed, the number, concentration and types of amino acids (Fig. 3 and Additional file 2: Table S3) differed significantly between the two accessions as was revealed by untargeted profiling of polar root exudates using GC-MS. Amino acids in root exudates have, beside sugars and sugar alcohols, been reported to tailor microbial communities, because they represent carbon and nitrogen substrates for microbial growth [60-62]. Previously, P deficiency was shown to stimulate the release of $\gamma$-aminobutyric acid and carbohydrates in maize grown hydroponically [17], as was observed for the C6 accession. However, the concentrations of these compounds in exudates from roots of the F103 accession were reduced under $P$ deficiency.

Exudation of organic acids by roots has been linked to $\mathrm{P}$ mobilisation in the soil [61], although the magnitude of the effect is debated [63] and there are large differences in the quantity and composition of organic acids released from roots among species and genotypes [16, 64]. In cabbage grown hydroponically, the exudation of citrate, malate and succinate was induced by P deficiency [65], as it was in canola grown in the soil [63], but not when canola was grown in sand culture supplied with different P sources [66]. The $\mathrm{P}$ mobilising ability of low-molecular-weight organic acids follows the order: citric $>$ oxalic $>$ tartaric $>$ malic acid [67]. Citric acid, the organic acid that most often increases in concentration in root exudates in response to P-deficiency [68] was not detected in our study. Instead, malic acid, in the $\mathrm{C} 6$ accession, and succinic acid, in the F103 accession, appeared to increase most in concentration in response to reduced $\mathrm{P}$ availability. The largest change in concentration in both accessions, although in opposite directions, was of 2-piperidinecarboxylic acid, whose role has not been studied in detail in root exudates but has been found to increase in A. thaliana roots when grown in alkaline solution [69]. Alkaline soil is known to reduce the availability of nutrients such as $\mathrm{P}$ [70]. It is possible that a compound like 2piperidinecarboxylic acid that might mobilise $\mathrm{P}$ in alkaline conditions might also contribute to $\mathrm{P}$ mobilising when $\mathrm{P}$ availability is restricted by a Low $P$ supply caused by inadequate total $\mathrm{P}$ concentrations in the soil.
Lateral roots play an important role in $\mathrm{P}$ acquisition by increasing soil exploration and the surface area of the root system for P uptake [14]. A greater number and length of lateral roots have been shown to contribute significantly to higher yields regardless of the external $P$ concentrations in genotypes with high P uptake efficiency [9]. The observed RSA with numerous long lateral roots closer to the upper parts of roots (first quartile) in the F103 accession (Fig. 4) matches the "topsoil foraging" phenotype, which is believed to be the most efficient root ideotype for efficient $\mathrm{P}$ acquisition $[5,8]$. In this accession, however, although relatively large shoot $\mathrm{P}$ concentrations were measured, this was not associated with a corresponding large biomass accumulation, which indicates poor physiological P-use efficiency [9]. In the HTRP experiment the largest concentrations of $\mathrm{P}$ in root cross sections was found in the endodermis (Fig. 5) in agreement with previous reports in various plant species [39, 41, 42, 71]. The endodermis represents a key apoplastic barrier to the radial transport of water and ions to the vascular system of the plant and as such it acts as a checkpoint in nutrient delivery to the shoot [27]. The observation that the C6 accession accumulated slightly more $\mathrm{P}$ in the endodermis at the High P supply than the F103 accession, could not be correlated with any of the traits studied, including differences in the P translocation factor. Further studies will be required to determine whether there is any link between $\mathrm{P}$ accumulation in the endodermis and a physiological function.

Despite accession C6 having fewer, and shorter, lateral roots than the F103 accession, the root cross section diameter was larger in the $\mathrm{C} 6$ accessions compared to the F103 accession receiving Low $P$ supply (Fig. 5a). The size of the root cross sections was investigated because common bean (Phaseolus vulgaris L.) genotypes with reduced root secondary growth, which caused smaller root cross sectional areas, smaller root respiration, and longer roots than other genotypes) produced significantly larger shoot biomass and contained larger shoot $\mathrm{P}$ concentrations than other genotypes when grown with a low $\mathrm{P}$ supply [72]. However, PERs were not significantly different between common bean genotypes with reduced or advanced secondary growth of roots [72]. In the study described here the largest root diameter (Fig. 5) coincided with the largest PER (Fig. 1f), which occurred in the C6 accession receiving the Low P supply. It may be that other root traits, such as biochemical traits, which were not studied by [72], contributed to the greater PER. Indeed, in response to limiting soil $\mathrm{P}$, species with thicker roots relied predominantly on higher solonisation by AMF to compensate for a low root absorptive surface and/or more P-mobilizing exudates to mine sparingly soluble $\mathrm{P}$ in the rhizosheath [73].

The large differences in metabolic and morphological root traits studied in the two accessions were supported 
by extensive differences in the DEGs in roots of the two accessions illustrated both as GO enrichments and MapMan analysis (Fig. 6). More DEGs in roots were accessionspecific than were common to both accessions. The F103 accession responded to the Low $P$ supply with more DEGs in roots than the C6 accession. Even when the GO enrichment was found to be common to both accessions, namely "glycolipid biosynthetic process" and "cellular response to starvation", the responses in the F103 accession were more significant. Lipids play crucial roles in the ability of plants to acclimate to, and survive, $\mathrm{P}$ scarcity [74-76], because some phospholipids can be replaced with non-phosphorus glycolipids and sulfolipids [77]. In general, the majority of GO processes were accession-specific, an observation which was further supported by the MapMan analysis of the gene expression of $B$. oleracea, annotated with their $A$. thaliana orthologues (Fig. 6c). The cell function overview showed repression for categories such as "metal handling" in the C6 accession with Low P supply. In this category, expression of genes linked with Fe homeostasis (such as Ferric Reduction Oxidase 2 (FRO2), Ferric Reductase Defective (FRD3) and Nicotianamine Synthase 2 (NAS2) [78]) were strongly down-regulated in the C6 accession in the Low P treatment. However, these expression changes were not accompanied by significant differences in root or shoot Fe concentrations (Additional file 1: Fig. S3). These observations are in contrast to previous observations in $A$. thaliana in which Fe acquisition was greater in P-deficient plants than in P-sufficient plants and the induction of different Fe homeostasis genes, such as NAS3 and FER1, were correlated with P-depletion [79]. The difference in response of $B$. oleracea and $A$. thaliana might be related to the $\mathrm{Fe}$ concentration in roots of $B$. oleracea accessions grown in the Low $P$ treatment being smaller than when grown in the High $P$ treatment (Additional file 1: Fig. S3), while the opposite was observed in A. thaliana. It is also possible that the response studied here is species specific, highly dynamic, depends on the level of P-deprivation stress or is related to other environmental factors, such as medium composition or the amount of available Fe. In addition, $A$. thaliana has been shown to have a very specific Feresponse to low $\mathrm{P}$ supply. For example, in $A$. thaliana an Fe-toxicity related reduction of main root elongation occurs at low P supply, which is uncommon in other plant species [80]. The expression of genes associated with "transport" processes, such as those encoding the $\mathrm{H}^{+}$-exporting ATPase (AHA2), Nitrate Transporter 2;1 (NRT2;1), Phosphate Transporter 1;4 (PHT1;4), Phosphate Transporter 3 (PHT3), Iron-Regulated Transporter 1 (IRT1) and a High Affinity potassium transporter (HAK5), responded in a complex manner to contrasting $\mathrm{P}$ supply, perhaps reflecting the network of interactions between elements in plants [81]. These changes might allow interesting insights to elemental homeostasis at low P supply. Overall, our analysis of gene expression highlights the distinct responses of the C6 and the F103 accessions to P deprivation as well as their common response of altering lipid biosynthesis. In addition, both C6 and F103 appear to utilise ROS signalling pathways to induce responses to Low P supply and induce phosphotransferases and phosphatases.

Interactions between $\mathrm{P}$ and $\mathrm{Zn}$ were also evaluated, since a negative relationship between increasing $P$ supply and shoot $\mathrm{Zn}$ concentration was expected based on observations in several crops $[23,31,33,82]$ and because the shoot concentration of no other element measured responded to genotype, treatment and their interaction (Additional file 1: Fig. S3). In addition, low P supply has been reported to result in shoot Zn-overaccumulation [22, 24, 25]. In efforts to increase shoot $\mathrm{Zn}$ concentration in edible crops to improve human $\mathrm{Zn}$ nutrition [83, 84], the first interaction is undesired and therefore crops or varieties with the ability to circumvent it are being sought. Although there was a clear response in root $\mathrm{Zn}$ concentrations with increasing $\mathrm{P}$ supply in both accession (Fig. 1g), only in the shoot of the F103 accession was $\mathrm{Zn}$ concentration increased in response to High $P$ supply (Fig. 1h). This observation differs from previous observation in the majority of $B$. oleracea genotypes [23] and mustard (Brassica juncea (L.) Czern.) [32, 82] in which shoot $\mathrm{Zn}$ concentrations were reduced by increasing $\mathrm{P}$ supply. Indeed, shoot $\mathrm{Zn}$ concentrations in both the C6 and F103 accessions were reduced when plants were grown in peat-based compost with increasing P supply [23].

Since there was no significant response in the number of lateral roots or their length in the two accessions in any of the root quartiles, it appears that root architecture did not play a role in their contrasting $\mathrm{Zn}$ acquisition. However, lateral root density of field-grown oilseed rape, but not primary root length and lateral root length, was significantly positively related to leaf $\mathrm{Zn}$ concentrations [85]. Larger shoot Zn concentrations in the F103 accession than in the C6 accession were also reported by [23] (Additional file 2: Table S7), which suggests these two accessions differ in their ability to accumulate Zn. Indeed, greater expression of a gene encoding a putative $\mathrm{Zn}$-transporter in roots of the F103 accession than in roots of the $\mathrm{C} 6$ accession was observed when plants were grown in an experiment with the same design with sufficient $\mathrm{Zn}$ supply [29]. Since $\mathrm{Zn}$ translocation factors did not differ between the two accessions, although there was a decrease in translocation of $\mathrm{Zn}$ when plants received High $P$ supply compared to the Low P supply, it appears that the $\mathrm{Zn}$ uptake into roots played a significant role in achieving higher $\mathrm{Zn}$ concentration in shoots.

\section{Conclusions}

The results obtained from the experiments performed here demonstrate extensive within-species differences in the responses of the ionome, root exudate composition 
and gene expression to the two $\mathrm{P}$ treatments studied. They provide a basis for experiments in mini-rhizotron systems that enable non-destructive root imaging and analysis $[11,86]$, which will provide validation of the results in a more realistic environment.

\section{Methods}

\section{Plant materia}

Two B. oleracea accessions: C6 ("Winterbor F1" kale, B. oleracea var. sabellica) and F103 (broccoli, B. oleracea var. italica) with contrasting P use efficiencies (Additional file 2: Table S7) were investigated. The choice of these two accessions was made by stepwise selection. First, eight accessions with a contrasting $\mathrm{P}$ use efficiency measure, namely the $\mathrm{P}$ efficiency ratio (PER) calculated as Yield low $\mathrm{P}_{\mathrm{P}} /\left(\mathrm{P}_{\text {low } \mathrm{P}} \times\right.$ Yield $\left._{\text {low } \mathrm{P}}\right)$ or Yield $\mathrm{Yigh}_{\mathrm{P}} /\left(\mathrm{P}_{\text {high } \mathrm{P}} \times\right.$ Yield $_{\text {high } \mathrm{P}}$ ), were selected from a diversity foundation set of 376 genotypes of B. oleracea $[9,23]$. Second, these eight accessions were grown hydroponically for 2 weeks with different combinations of P and Zn supply and two accessions, F103 and C6, were selected based on the contrasting responses of their ionomes to these treatments [29]. Seeds of the F103 accession were obtained from the Genetic Resource Unit, Warwick Crop Centre of the University of Warwick (where this accession is kept under the HRIGRU04701 number; https://warwick.ac.uk/ $\mathrm{fac} / \mathrm{sci} /$ lifesci/wcc/gru/). Seeds of the C6 accession were commercially available from Sakata Seed America Inc. (https:// www.sakata.com/) as a Winderbore F1 genotype with the common name of Borecole. The accessions were first grown in a glasshouse for seeds (seed bulking). For the hydroponic experiments, these seeds were germinated on the surface of filter paper moistened with deionised water in a Petri dish placed at $16^{\circ} \mathrm{C}$ in the dark for 5 days. For high throughput root phenotyping (HTPR) experiments, seeds were used directly, without pre-germination, and were placed onto blue germination paper.

\section{Hydroponic experiments}

The two $B$. oleracea accessions were grown at two different P concentrations: $0.025 \mathrm{mM} \mathrm{P}($ Low $P)$ and $0.25 \mathrm{mM}$ $\mathrm{P}$ (High P). The High $P$ nutrient solution contained 2 $\mathrm{mM} \mathrm{Ca}\left(\mathrm{NO}_{3}\right)_{2}, 2 \mathrm{mM} \mathrm{NH}_{4} \mathrm{NO}_{3}, 0.75 \mathrm{mM} \mathrm{MgSO}_{4}, 0.5$

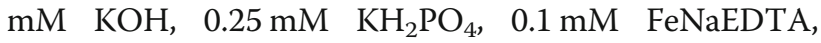
$30 \mu \mathrm{M} \quad \mathrm{H}_{3} \mathrm{BO}_{3}, 25 \mu \mathrm{M} \quad \mathrm{CaCl}_{2}, \quad 10 \mu \mathrm{M} \quad \mathrm{MnSO}_{4}, 3 \mu \mathrm{M}$ $\mathrm{CuSO}_{4}, 1 \mu \mathrm{M} \mathrm{ZnSO}$ and $0.5 \mu \mathrm{M} \mathrm{Na}_{2} \mathrm{MoO}_{4}$. The Low $P$ nutrient solution had a similar composition, except that it contained $0.025 \mathrm{mM} \mathrm{KH}_{2} \mathrm{PO}_{4}$ and $0.225 \mathrm{mM} \mathrm{KCl}$ to provide an equivalent $\mathrm{K}$ supply. The experiment was performed as described in detail previously [29]. There were four buckets (24 plants) for each accession and each treatment.

\section{Gene expression study through RNAseq analysis}

Procedures for RNA extraction from roots $(n=3)$, library preparation, sequencing and bioinformatics analysis have been described in detail previously [29]; this previously published RNAseq dataset was processed anew by concentrating solely on the two $\mathrm{P}$ treatments: the Low $P$ and the High $P$ treatments. Differentially expressed genes (DEGs) were calculated as a ratio of the gene expression in the Low $P$ treatment in comparison to the gene expression in the High $P$ treatment. A filter of fold change $>2$ and a diverge probability greater than or equal to $80 \%$ was applied to define the P-responsive DEGs. Significantly enriched gene ontology (GO) terms were also sought based on "GO Term Finder" (http:// www.yeastgenome.org/help/analyze/go-term-finder). The $B$. oleracea orthologues of $A$. thaliana genes were sought using the BioMart tool of EnsemblPlants release 46 [87]. The $A$. thaliana orthologues for the P-responsive DEGs in B. oleracea accessions C6 and F103 were identified using Ensembl. Of all 447 P-responsive DEGs in B. oleracea, 354 orthologues were identified in A. thaliana and the expression data for these was loaded into MapMan Version 3.5.0 BETA (https://mapman.gabipd.org/home) to analyse pathways affected by a reduced $\mathrm{P}$ supply. Line graphs were drawn in $\mathrm{R}$, ggplot2 package [88], using MapMan outputs.

\section{Collection and metabolome profiling of root exudates}

Since optimal root exudate collection by washing in trap solution is considered to be $2-6 \mathrm{~h}$ [59], the hydroponically-grown plants were placed (individually) in $100 \mathrm{~mL}$ of MilliQ water for $3 \mathrm{~h}$ (half of this time in the dark), frozen (at $-20^{\circ} \mathrm{C}$ ) and freeze dried (Alpha 24 , Christ, Germany) for 3 days $\left(-50^{\circ} \mathrm{C}, 0.12 \mathrm{mbar}\right)$. However, this procedure yielded too small an amount of root exudates for all the analyses planned. Therefore, we repeated the experiment and exudates were collected over a period of twelve hours (half of this time in the dark), frozen and freeze dried. Still, the amount collected was not enough for the analyses planned. The results reported here came from a third attempt, when eighteen individuals of each accession from each treatment were placed in $100 \mathrm{~mL}$ of MilliQ water (without aeration), where they were kept for $24 \mathrm{~h}$ (half of this time in the dark) in the same greenhouse where the plants were grown. At the end of the collection period, in the morning, plants were removed from the solution, which was filtered $(0.44 \mu \mathrm{m}$, Sigma-Aldrich), frozen and freeze dried. From the latter protocol, $0.9-3.8 \mu \mathrm{g}$ of root exudates were collected for each treatment.

One half of each of the root exudate dry matter collected was used for the preliminary investigation of major functional groups using Fourier Transform Infrared (FTIR) spectroscopy, which was carried out at Beamline ID21 at the European Synchrotron Radiation Facility (ESRF) in Grenoble, France. Analysis was conducted on the Thermo Nicolet Nexus spectrometer (Artisan Technology Group, Champaign, IL, USA) 
associated with a SMART-orbit Attenuated Total Reflection (ATR) accessory as described previously [89]. All acquisitions were performed in the mid-IR spectral range $\left(1700-800 \mathrm{~cm}^{-1}\right)$ in air.

On the second half of each of the root exudates collected, polar compounds were extracted and derivatised as described previously [90] and metabolite profiles were acquired using a gas chromatography-mass spectrometer (GC-MS; DSQII, Thermo-Finnigan, Hemel Hempstead, UK) system using a DB5-MSTM column $(15 \mathrm{~m} \times 0.25 \mathrm{~mm} \times 0.25 \mu \mathrm{m}$; J\&W, Folsom, CA, USA) as described by [91]. Compounds were identified by their mass spectrum and co-elution with authentic standards as determined using an in-house database. Data is presented as a relative value based upon the peak area of the specific ion used for quantification.

\section{Analysis of concentrations of elements in roots and shoots}

Concentrations of $\mathrm{P}$, sulphur (S), potassium (K), calcium $(\mathrm{Ca})$, manganese $(\mathrm{Mn})$, iron $(\mathrm{Fe})$ and $\mathrm{Zn}$ were determined in oven-dried $\left(70{ }^{\circ} \mathrm{C}\right.$ for 3 days) roots $(n=5-7$, composite samples from the initial 18 individuals used for the exudate collection) and shoots $(n=6)$ using inductively coupled plasma-mass spectrometry (ICP-MS) after microwave-assisted acid digestion as described by [92] Phosphorus contents in root, shoots and whole plants were calculated by multiplying the $\mathrm{P}$ concentration in the respective organ with its corresponding biomass.

\section{High throughput root phenotyping (HTRP) experiment}

Root system architecture was studied in a system similar to the one described by [85]. Seeds were placed on germination paper moistened with the same nutrient solutions used in the hydroponic experiments. Experiments were performed in $25 \times 25 \mathrm{~cm}$ Petri dishes, which were arranged vertically in a growth chamber (maintained at, on average, $16^{\circ} \mathrm{C}$ during $8 \mathrm{~h}$ night and $18{ }^{\circ} \mathrm{C}$ during the 16 h day). After 2 weeks of growth, roots were photographed and the length of the main root, and the number and length of lateral roots in each quartile of the main root length was determined using Fiji image processing software [93]. Three independent experiments were conducted, each having 8-11 replicates of each accession and treatment.

\section{Phosphorus distribution in roots}

Plants from the HTRP experiments were used for the determination of $\mathrm{P}$ distribution in roots using microproton induced X-ray emission (micro-PIXE). Samples were prepared as described previously [94]. Pieces of roots below the first lateral root were placed into stainless-steel needles, cryo-fixed, cryo-sectioned to $50 \mu \mathrm{m}$ thickness, freeze dried and sandwiched between two Pioloform foils (approx. $400 \mathrm{~nm}$ thickness; SPI supplies, West Chester, PA, USA) stretched over an aluminium frame. Micro-PIXE analysis was performed as described previously [95]. The micro-PIXE spectra were analysed and distribution maps were generated in the GeoPIXE II software package [96]. Because the distribution maps are quantitative each pixel provides information on the concentration of an element. Therefore, P concentrations were extracted from whole cross sections and from the endodermis of each section measured. In addition, the root cross-section diameter was determined. These calculations were performed using Fiji image processing software [93] as described previously [94].

\section{Statistical analysis}

One-way analysis of variance (ANOVA) with accession as the independent variable and two-way ANOVA with accession and treatment as independent variables followed by a Holm-Sidak post-hoc test at $p<0.05$ were employed when data were normally distributed. A nonparametric test (ANOVA on ranks, followed by Dunn's test at $p<0.05)$ was employed in the case of nonparametric (lateral root length) data. The Student t-test (at $p<0.05$ ) was used for comparisons of two groups. All statistical analyses were performed in SigmaPlot version 13.0 (Systat Software, San Jose, CA). The processing of ATR-FTIR spectra and the principal component analysis (PCA) for these spectra were performed using Orange 3.18 software [97, 98] and the workflow is shown in Additional file 1: Fig. S5. Data pre-processing for the PCA consisted of ATR correction using OMNIC Spectra (Thermo Fischer Scientific $\odot$ ) followed by rubber band baseline correction and vector normalisation.

\section{Supplementary information}

Supplementary information accompanies this paper at https://doi.org/10. 1186/s12870-020-02558-2.

\footnotetext{
Additional file 1 Fig. S1. Growth of Brassica oleracea accessions (C6 and F103) cultivated hydroponically for 2 weeks in solutions containing 0.025 mM P (Low P) and 0.25 mM P (High P). Fig. S2. Root (a), shoot (b) and plant (c) phosphorus (P) content of two Brassica oleracea accessions (C6 and F103) grown hydroponically for 2 weeks in solutions containing $0.025 \mathrm{mM} \mathrm{P}$ (LoW P; LP) and 0.25 mM P (High P; HP). Data are means ( $n=$ 5-6) and standard errors. Asterisks indicate statistically significant differences (two-way analysis of variance followed by Holm-Sidak post hoc test at $P<0.05)$. Fig. S3. Root and shoot concentrations of calcium (Ca), sulphur (S), potassium (K), manganese $(\mathrm{Mn})$ and iron $(\mathrm{Fe})$ of two Brassica oleracea accessions (C6 and F103) grown hydroponically for 2 weeks in solutions containing $0.025 \mathrm{mM} \mathrm{P}$ (Low P; LP) and $0.25 \mathrm{mM} \mathrm{P}$ (High P; HP). Data are means $(n=5-6)$ and standard errors. Asterisks indicate statistically significant differences (two-way analysis of variance followed by Holm-Sidak post hoc test at $P<0.05$ ). Fig. S4. Contributions of functional bands in the Fourier Transform Infrared spectra of root exudates collected from two Brassica oleracea accessions (C6 and F103) grown hydroponically for 2 weeks in solutions containing $0.025 \mathrm{mM} \mathrm{P}$ (Low P) and $0.25 \mathrm{mM} \mathrm{P} \mathrm{(High} \mathrm{P)} \mathrm{to} \mathrm{the} \mathrm{principal} \mathrm{component} \mathrm{one} \mathrm{(PC1)}$ and principal component two (PC2; PCA plot in Fig. 3b of the main text). Fig. S5. Workflow of the processing of the Fourier transform infrared spectroscopy spectra in Orange 3.18 software [1, 2].
} 
Additional file 2 Table S1. Two-way analysis of variance (ANOVA) table with $p$ values (those less than $5 \%$ are highlighted in bold) and means squares (in italics) for response variables in two Brassica oleracea accessions (C6 and F103) grown hydroponically for 2 weeks in solutions containing 0.025 mM P (Low P) or 0.25 mM P (High P); Zn, zinc. Table S2. Relative concentration of polar metabolites detected in root exudates of two Brassica oleracea accessions (C6 and F103) grown hydroponically for 2 weeks in solutions containing $0.025 \mathrm{mM} \mathrm{P}$ (Low P) or $0.25 \mathrm{mM} \mathrm{P}$ (High P). * indicates metabolites for which fold change could not be calculated, as it was not detected in one of the treatments in both accessions. Table S3. Two-way analysis of variance (ANOVA) table with $p$ values (those less than $5 \%$ are highlighted in bold) and means squares (in italics) for main root length and ANOVA on Ranks for lateral root length along the main root length, divided into quartiles, in two Brassica oleracea accessions (C6 and F103) grown in the high throughput root phenotyping system with Low phosphorus $(P)$ and High $P$ treatments (four groups in total) for 2 weeks. Table S4. All differentially expressed P-responsive genes and their expression in FPKM, in roots of two Brassica oleracea accessions (C6 and F103) grown hydroponically for 2 weeks in solutions containing $0.025 \mathrm{mM}$ P (Low P; LP) and $0.25 \mathrm{mM}$ P (High P; HP). Differentially expressed genes were defined by comparing the gene expression in the Low $\mathrm{P}$ treatment with the gene expression in the High $\mathrm{P}$ treatment for each of the B. oleracea accession. Table S5. Gene ontology enrichment analysis for all differentially expressed genes in roots of two Brassica oleracea accessions (the C6 and the F103) grown in solutions containing $0.025 \mathrm{mM} \mathrm{P}$ (Low P) and $0.25 \mathrm{mM} \mathrm{P}$ (High P) for 2 weeks ( $n=3$ for each accession and each treatment). Bonferroni corrected $p$-values were used to determine significantly enriched categories and a corrected $p$-value of 0.05 was used as a cut-off. Table S6. P-responsive genes with orthologues in Arabidopsis thaliana. The table shows the gene expression of all P-responsive genes in the roots of two Brassica oleracea accessions (C6 and F103) grown hydroponically for 2 weeks in solutions containing $0.025 \mathrm{mM}$ P (Low P) and $0.25 \mathrm{mM}$ P (High P) which have A. thaliana ortholouges. Table S7. Shoot fresh weight, phosphorus (P) and zinc (Zn) concentrations and $\mathrm{P}$ efficiency ratio (calculated as Yield $\mathrm{l}_{\text {low }} /\left(\mathrm{P}_{\text {low }} \times\right.$ Yiel$\left.d_{\text {low }}\right)$ or Yield $d_{\text {high }} /\left(P_{\text {high }} \times\right.$ Yield $\left.d_{\text {high }}\right)$ ) of the two Brassica oleracea accessions (C6 and F103) grown in a peat-based compost amended with Low P $\left(5.25 \mathrm{mg} \mathrm{L}^{-1}\right)$ and High P $\left(15.75 \mathrm{mg} \mathrm{L}^{-1}\right)$ used in the experiments. Data for fresh weight, shoot $P$ concentration and $P$ efficiency ratio are from [1] and shoot Zn concentrations are from [2]; DM, dry matter.

\section{Abbreviations}

AHA2: $\mathrm{H}^{+}$-exporting ATPase; ATR-FTIR: Attenuated Total Reflectance - Fourier Transform InfraRed; Ca: Calcium; DEG: Differentially expressed gene; Fe: Iron; FER1: Ferritin-1; FRD3: Ferric Reductase Defective; FRO2: Ferric Reduction Oxidase 2; GC-MS: Gas chromatography - mass spectrometry; GO: Gene ontology; HAK5: High Affinity potassium transporter HAK5; HTRP: Highthroughput root phenotyping; ICP-MS: Inductively coupled plasma - mass spectrometry; IRT1: Iron-Regulated Transporter 1; K: Potassium; MicroPIXE: Micro-particle induced - X-ray emission; Mn: Manganese; NAS: Nicotianamine Synthase; NRT2;1: Nitrate Transporter 2;1; P: Phosphorus; PHT: Phosphate Transporter; PC: Principal component; RSA: Root system architecture; S: Sulphur; Zn: zinc

\section{Acknowledgements}

Authors are grateful to Dr. Tim George and Lawrie Brown for their advice about collecting root exudates and to Dr. Jaswant Singh Khokhar and Lolita Wilson for their advice about the high-throughput root phenotyping experiments. We also thank David E. Salt at the University of Nottingham for his mentorship of Sina Fischer.

\section{Authors' contributions}

PPo and PJW conceived and designed the research and wrote the manuscript. PPo and GW conducted the experiments, JAT performed ICP-MS analysis, HC-M and JRH performed ATR-FTIR analysis and spectra processing, RDH performed GC-MS analysis, MK, PV and PPe performed the micro-PIXE analysis, ML provided statistical advice and contributed improvements to figures, MRB supported the HTRP experiments, and SF performed bioinformatics on the RNAseq, designed the relevant figure, and contributed to the revision. All authors approved the manuscript.

\section{Funding}

This work was supported by the Rural and Environment Science and Analytical Services Division of the Scottish Government and an EU Marie Curie Intra-European Fellowship (REA grant agreement $n^{\circ}$ 623305) to Paula Pongrac, who also acknowledges financial support from the Slovenian Research Agency (Research programmes P1-0212 and P1-0112, and projects N7-0077 and J7-9398). Juan Reyes-Herrera acknowledges the Mexican National Council for Science and Technology (CONACYT) for the funding of his post-doctoral position (CONACYT CVU\#177448).

\section{Availability of data and materials}

The datasets generated during and/or analysed during the current study are available from the corresponding author on reasonable request. RNAseq data can be found in Gene Expression Omnibus under the accession number GSE127467 (https://www.ncbi.nlm.nih.gov/geo/query/acc.cgi?acc= GSE127467).

\section{Ethics approval and consent to participate}

Not applicable.

\section{Consent for publication}

Not applicable.

\section{Competing interests}

The authors declare that they have no conflict of interest.

\section{Author details}

${ }^{1}$ Ecological Science Group, The James Hutton Institute, Invergowrie, Dundee DD2 5DA, UK. ${ }^{2}$ Jožef Stefan Institute, Jamova 39, SI-1000 Ljubljana, Slovenia. ${ }^{3}$ European Synchrotron Radiation Facility, Grenoble, France. ${ }^{4}$ Cell and Molecular Sciences, The James Hutton Institute, Invergowrie, Dundee DD2 5DA, UK. ${ }^{5}$ Future Food Beacon of Excellence and the School of Biosciences, University of Nottingham, Nottingham LE12 5RD, UK. ${ }^{6}$ Jožef Stefan International Postgraduate School, Jamova 39, SI-1000 Ljubljana, Slovenia. ${ }^{7}$ Biotechnical Faculty, University of Ljubljana, Jamnikarjeva 101, SI-1000 Ljubljana, Slovenia. ${ }^{8}$ Plant and Crop Sciences Division, University of Nottingham, Loughborough LE12 5RD, UK. ${ }^{9}$ Distinguished Scientist Fellowship Program, King Saud University, Riyadh 11451, Saudi Arabia. ${ }^{10}$ College of Resources and Environment, Huazhong Agricultural University, Wuhan 430070, China.

Received: 14 August 2019 Accepted: 19 July 2020

Published online: 05 August 2020

\section{References}

1. Veneklaas EJ, Lambers H, Bragg J, Finnegan PM, Lovelock CE, Plaxton WC, et al. Opportunities for improving phosphorus-use efficiency in crop plants. New Phytol. 2012;195:306-20. https://doi.org/10.1111/j.1469-8137.2012. 04190.x.

2. Lambers H, Plaxton WC. Phosphorus: Back to the roots. In: Annual Plant Reviews, vol. 48: Wiley-Blackwell; 2015. p. 1-22. https://doi.org/10.1002/ 9781118958841.ch1.

3. Baker A, Ceasar SA, Palmer AJ, Paterson JB, Qi W, Muench SP, et al. Replace, reuse, recycle: improving the sustainable use of phosphorus by plants. J Exp Bot. 2015;66:3523-40. https://doi.org/10.1093/jxb/erv210.

4. Scheible W-R, Rojas-Triana M. Sensing, signalling, and control of phosphate starvation in plants: molecular players and applications. In: Annual Plant Reviews volume 48. Hoboken: John Wiley \& Sons, Inc.; 2015. p. 23-63. https://doi.org/10.1002/9781118958841.ch2.

5. White PJ, George TS, Gregory PJ, Bengough AG, Hallett PD, McKenzie BM. Matching roots to their environment. Ann Bot. 2013;112:207-22. https://doi. org/10.1093/aob/mct123.

6. Rose TJ, Impa SM, Rose MT, Pariasca-Tanaka J, Mori A, Heuer S, et al. Enhancing phosphorus and zinc acquisition efficiency in rice: a critical review of root traits and their potential utility in rice breeding. Ann Bot. 2013;112:331-45. https://doi.org/10.1093/aob/mcs217.

7. Wang W, Ding G-D, White PJ, Wang X-H, Jin K-M, Xu F-S, et al. Mapping and cloning of quantitative trait loci for phosphorus efficiency in crops: opportunities and challenges. Plant Soil. 2019;439:91-112. https://doi.org/10. 1007/s11104-018-3706-6. 
8. Lynch JP. Root phenes for enhanced soil exploration and phosphorus acquisition: tools for future crops. Plant Physiol. 2011;156:1041-9. https://doi. org/10.1104/pp.111.175414.

9. Hammond JP, Broadley MR, White PJ, King GJ, Bowen HC, Hayden R, et al. Shoot yield drives phosphorus use efficiency in Brassica oleracea and correlates with root architecture traits. J Exp Bot. 2009;60:1953-68. https:// doi.org/10.1093/jxb/erp083

10. Ao J, Fu J, Tian J, Yan X, Liao H. Genetic variability for root morph-architecture traits and root growth dynamics as related to phosphorus efficiency in soybean. Funct Plant Biol. 2010;37:304. https:/doi.org/10.1071/FP09215.

11. Yuan P, Ding G-D, Cai H-M, Jin K-M, Broadley MR, Xu F-S, et al. A novel Brassica-rhizotron system to unravel the dynamic changes in root system architecture of oilseed rape under phosphorus deficiency. Ann Bot. 2016; 118:173-84. https://doi.org/10.1093/aob/mcw083.

12. Péret $B$, Clément $M$, Nussaume $L$, Desnos $T$. Root developmental adaptation to phosphate starvation: better safe than sorry. Trends Plant Sci. 2011;16: 442-50. https://doi.org/10.1016/j.tplants.2011.05.006.

13. Bhosale R, Giri J, Pandey BK, Giehl RFH, Hartmann A, Traini R, et al. A mechanistic framework for auxin dependent Arabidopsis root hair elongation to low external phosphate. Nat Commun. 2018;9:1-9. https://doi. org/10.1038/s41467-018-03851-3.

14. Niu YF, Chai RS, Jin GL, Wang H, Tang CX, Zhang YS. Responses of root architecture development to low phosphorus availability: a review. Ann Bot. 2013;112:391-408. https://doi.org/10.1093/aob/mcs285.

15. Lynch JP. Root phenotypes for improved nutrient capture: an underexploited opportunity for global agriculture. New Phytol. 2019:0-2. https://doi.org/10.1111/nph.15738.

16. Wang $Y$, Lambers $H$. Root-released organic anions in response to low phosphorus availability: recent progress, challenges and future perspectives. Plant Soil. 2020;447:135-56. https://doi.org/10.1007/s11104-019-03972-8.

17. Carvalhais LC, Dennis PG, Fedoseyenko D, Hajirezaei M-R, Borriss R, von Wirén N. Root exudation of sugars, amino acids, and organic acids by maize as affected by nitrogen, phosphorus, potassium, and iron deficiency. J Plant Nutr Soil Sci. 2011;174:3-11. https://doi.org/10.1002/jpln.201000085.

18. Krishnapriya $V$, Pandey R. Root exudation index: screening organic acid exudation and phosphorus acquisition efficiency in soybean genotypes. Crop Pasture Sci. 2016;67:1096-109. https://doi.org/10.1071/CP15329.

19. Edayilam N, Montgomery D, Ferguson B, Maroli AS, Martinez N, Powell BA, et al. Phosphorus stress-induced changes in plant root exudation could potentially facilitate uranium mobilization from stable mineral forms. Environ Sci Technol. 2018;52:7652-62. https://doi.org/10.1021/acs.est.7b05836.

20. Valentinuzzi F, Pii Y, Vigani G, Lehmann M, Cesco S, Mimmo T. Phosphorus and iron deficiencies induce a metabolic reprogramming and affect the exudation traits of the woody plant Fragariaxananassa. J Exp Bot. 2015;66: 6483-95. https://doi.org/10.1093/jxb/erv364.

21. Pongrac $P$, MCNicol JW, Lilly A, Thompson JA, Wright G, Hillier S, et al. Mineral element composition of cabbage as affected by soil type and phosphorus and zinc fertilisation. Plant Soil. 2019;434:151-65. https://doi. org/10.1007/s11104-018-3628-3.

22. Misson J, Raghothama KG, Jain A, Jouhet J, Block MA, Bligny R, et al. A genome-wide transcriptional analysis using Arabidopsis thaliana Affymetrix gene chips determined plant responses to phosphate deprivation. Proc Natl Acad Sci. 2005;102:11934-9. https://doi.org/10.1073/pnas.0505266102.

23. Broadley M, Lochlainn S, Hammond J, Bowen H, Cakmak I, Eker S, et al. Shoot zinc $(\mathrm{Zn})$ concentration varies widely within Brassica oleracea $\mathrm{L}$. and is affected by soil Zn and phosphorus (P) levels. J Hortic Sci Biotechnol. 2010; 85:375-80. https://doi.org/10.1080/14620316.2010.11512683.

24. Briat J-F, Rouached H, Tissot N, Gaymard F, Dubos C. Integration of P, S, Fe, and $\mathrm{Zn}$ nutrition signals in Arabidopsis thaliana: potential involvement of PHOSPHATE STARVATION RESPONSE 1 (PHR1). Front Plant Sci. 2015:6:290. https://doi.org/10.3389/fpls.2015.00290.

25. Santos EF, Pongrac P, Reis AR, White PJ, Lavres J. Phosphorus-zinc interactions in cotton: consequences for biomass production and nutrientuse efficiency in photosynthesis. Physiol Plant. 2019;166:996-1007. https:// doi.org/10.1111/ppl.12867.

26. Cakmak I. Tansley review no.111: possible roles of zinc in protecting plant cells from damage by reactive oxygen species. New Phytol. 2000;146:185-205.

27. White PJ. Chapter 2 - Ion uptake mechanisms of individual cells and roots: Short-distance transport. In: Marschner P, editor. Marschner's Mineral Nutrition of Higher Plants (Third Edition). San Diego: Academic Press; 2012. p. 7-47. doi:https://doi.org/10.1016/B978-0-12-384905-2.00002-9.
28. Li S, Zhou X, Huang Y, Zhu L, Zhang S, Zhao Y, et al. Identification and characterization of the zinc-regulated transporters, iron-regulated transporter-like protein (ZIP) gene family in maize. BMC Plant Biol. 2013;13: 114. https://doi.org/10.1186/1471-2229-13-114

29. Pongrac P, Fischer S, Thompson JA, Wright G, White PJ. Early responses of Brassica oleracea roots to zinc supply under sufficient and sub-optimal phosphorus supply. Front Plant Sci. 2020;10:1-17. https://doi.org/10.3389/ fpls.2019.01645

30. Stukenholtz DD, Olsen RJ, Gogan G, Olson RA. On the mechanism of phosphorus-zinc interaction in corn nutrition. Soil Sci Soc Am J. 1966;30: 759-63. https://doi.org/10.2136/sssaj1966.03615995003000060029x.

31. Haldar M, Mandal LN. Effect of phosphorus and zinc on the growth and phosphorus, zinc, copper, iron and manganese nutrition of rice. Plant Soil. 1981;59:415-25. https://doi.org/10.1007/BF02184546.

32. Akhtar MS, Oki Y, Adachi T. Growth behavior, nitrogen-form effects on phosphorus acquisition, and phosphorus-zinc interactions in Brassica cultivars under phosphorus-stress environment. Commun Soil Sci Plant Anal. 2010;41:2022-45. https://doi.org/10.1080/00103624.2010.498534.

33. Zhang Y-Q, Deng Y, Chen R-Y, Cui Z-L, Chen X-P, Yost R, et al. The reduction in zinc concentration of wheat grain upon increased phosphorusfertilization and its mitigation by foliar zinc application. Plant Soil. 2012;361: 143-52. https://doi.org/10.1007/s11104-012-1238-z.

34. Li H - Y., Zhu Y -G., Smith SE, Smith FA. Phosphorus-zinc interactions in two barley cultivars differing in phosphorus and zinc efficiencies. J Plant Nutr 2003:26:1085-1099. doi:https://doi.org/10.1081/PLN-120020077.

35. Cakmak I. Enrichment of cereal grains with zinc: agronomic or genetic biofortification? Plant Soil. 2008;302:1-17. https:/doi.org/10.1007/s11104-007-9466-3.

36. Cakmak I, McLaughlin MJ, White PJ. Zinc for better crop production and human health. Plant Soil. 2017;411:1-4. https://doi.org/10.1007/s11104-016-3166-9.

37. White $P$, Pongrac $P$, Sneddon CC, Thompson JA, Wright G. Limits to the biofortification of leafy brassicas with zinc. Agriculture. 2018:8:32. https://doi. org/10.3390/agriculture8030032.

38. Conn S, Gilliham M. Comparative physiology of elemental distributions in plants. Ann Bot. 2010;105:1081-102.

39. Lyubenova L, Pongrac P, Vogel-Mikuš K, Mezek GK, Vavpetič P, Grlj N, et al. Localization and quantification of $\mathrm{Pb}$ and nutrients in Typha latifolia by micro-PIXE. Metallomics. 2012;4:333-41.

40. Tani T, Katsuki T, Okazaki Y, Arichi S. Histochemistry. X. Distributions of aluminum, phosphorus, and other elements in Bupleurum falcatum root cultivated in Japan. Chem Pharm Bull (Tokyo). 1987;35:3323-8.

41. Vogel-Mikuš K, Pongrac $P$, Pelicon $P$, Vavpetič $P$, Povh $B$, Bothe $H$, et al. Micro-PIXE analysis for localization and quantification of elements in roots of mycorrhizal metal-tolerant plants. In: Varma A, Kharkwal AC, editors. Symbiotic Fungi: Principles and Practice. Berlin: Springer Berlin Heidelberg; 2009. p. 227-42. https://doi.org/10.1007/978-3-540-95894-9_14.

42. Lu L, Xie R, Liu T, Wang H, Hou D, Du Y, et al. Spatial imaging and speciation of $\mathrm{Cu}$ in rice (Oryza sativa L.) roots using synchrotron-based $X$-ray microfluorescence and X-ray absorption spectroscopy. Chemosphere. 2017; 175:356-64. https://doi.org/10.1016/j.chemosphere.2017.02.082.

43. Raab T, Vogel J. Ecological and agricultural applications of synchrotron IR microscopy. Infrared Phys Technol. 2004;45:393-402. https://doi.org/10.1016/ j.infrared.2004.01.008.

44. da Luz BR. Attenuated total reflectance spectroscopy of plant leaves: a tool for ecological and botanical studies. New Phytol. 2006;172:305-18.

45. Regvar M, Eichert D, Kaulich B, Gianoncelli A, Pongrac P, Vogel-Mikuš K. Biochemical characterization of cell types within leaves of metalhyperaccumulating Noccaea praecox (Brassicaceae). Plant Soil. 2013;373.

46. Seyfferth AL, Webb SM, Andrews JC, Fendorf S. Arsenic localization, speciation, and co-occurrence with iron on rice (Oryza sativa L.) roots having variable Fe coatings. Environ Sci Technol. 2010;44:8108-13. https:// doi.org/10.1021/es101139z.

47. Kopittke PM, de Jonge MD, Menzies NW, Wang P, Donner E, McKenna BA, et al. Examination of the distribution of arsenic in hydrated and fresh cowpea roots using two- and three-dimensional techniques. Plant Physiol. 2012;159:1149-58. https://doi.org/10.1104/pp.112.197277.

48. Song J, Yang YQ, Zhu SH, Chen GC, Yuan XF, Liu TT, et al. Spatial distribution and speciation of copper in root tips of cucumber revealed by $\mu$-XRF and $\mu$-XANES. Biol Plant. 2013:57:581-6.

49. Shi J, Gras MA, Silk WK. Laser ablation ICP-MS reveals patterns of copper differing from zinc in growth zones of cucumber roots. Planta. 2009;229:945-54. 
50. Jiang C, Gao X, Liao L, Harberd NP, Fu X. Phosphate starvation root architecture and anthocyanin accumulation responses are modulated by the gibberellin-DELLA signaling pathway in Arabidopsis. Plant Physiol. 2007; 145:1460-70. https://doi.org/10.1104/pp.107.103788.

51. White PJ, Brown PH. Plant nutrition for sustainable development and global health. Ann Bot. 2010;105:1073-80.

52. Raven JA, Lambers $H$, Smith SE, Westoby M. Costs of acquiring phosphorus by vascular land plants: patterns and implications for plant coexistence. New Phytol. 2018;217:1420-7.

53. Guyonnet JP, Guillemet M, Dubost A, Simon L, Ortet P, Barakat M, et al. Plant nutrient resource use strategies shape active rhizosphere microbiota through root exudation. Front Plant Sci. 2018;9:1-13. https://doi.org/10. 3389/fpls.2018.01662.

54. Hu L, Robert CAM, Cadot S, Zhang X, Ye M, Li B, et al. Root exudate metabolites drive plant-soil feedbacks on growth and defense by shaping the rhizosphere microbiota. Nat Commun. 2018;9:1-13.

55. Lesuffleur F, Paynel F, Bataillé MP, Le Deunff E, Cliquet JB. Root amino acid exudation: measurement of high efflux rates of glycine and serine from six different plant species. Plant Soil. 2007;294:235-46.

56. Neumann S, Schmidt S, Strehmel N, Müller E, Taruttis F, Scheel D, et al. Natural variation of root exudates in Arabidopsis thaliana-linking metabolomic and genomic data. Sci Rep. 2016;6:1-11. https://doi.org/10. 1038/srep29033.

57. Cakmak I, Marschner H. Increase in membrane permeability and exudation in roots of zinc deficient plants. J Plant Physiol. 1988;132:356-61. https://doi. org/10.1016/S0176-1617(88)80120-2

58. Aulakh MS, Wassmann $\mathrm{R}$, Bueno $\mathrm{C}$, Kreuzwieser J, Rennenberg $\mathrm{H}$. Characterization of root exudates at different growth stages of ten rice (Oryza sativa L.) cultivars. Plant Biol. 2001;3:139-48.

59. Neumann G, George TS, Plassard C. Strategies and methods for studying the rhizosphere---the plant science toolbox. Plant Soil. 2009;321:431-56. https://doi.org/10.1007/s11104-009-9953-9.

60. Baetz U, Martinoia E. Root exudates: the hidden part of plant defense. Trends Plant Sci. 2014;19:90-8. https://doi.org/10.1016/j.tplants.2013.11.006.

61. Sasse J, Martinoia E, Northen T. Feed your friends: do plant exudates shape the root microbiome? Trends Plant Sci. 2018;23:25-41. https://doi.org/10. 1016/j.tplants.2017.09.003.

62. Castrillo G, Teixeira PJPL, Paredes SH, Law TF, de Lorenzo L, Feltcher ME, et al. Root microbiota drive direct integration of phosphate stress and immunity. Nature. 2017:543:513-8. https://doi.org/10.1038/nature21417.

63. Wang Y, Krogstad T, Clarke JL, Hallama M, Øgaard AF, Eich-Greatorex S, et al. Rhizosphere organic anions play a minor role in improving crop species ability to take up residual phosphorus $(\mathrm{P})$ in agricultural soils low in $\mathrm{P}$ availability. Front Plant Sci. 2016:1-14. https://doi.org/10.3389/fpls.2016. 01664.

64. Pandey R, Meena SK, Krishnapriya V, Ahmad A, Kishora N. Root carboxylate exudation capacity under phosphorus stress does not improve grain yield in green gram. Plant Cell Rep. 2014;33:919-28.

65. Dechassa N, Schenk MK. Exudation of organic anions by roots of cabbage, carrot, and potato as influenced by environmental factors and plant age. J Plant Nutr Soil Sci. 2004;167:623-9.

66. Pearse SJ, Veneklaas EJ, Cawthray G, Bolland MDA, Lambers H. Carboxylate composition of root exudates does not relate consistently to a crop species ability to use phosphorus from aluminium, iron or calcium phosphate sources. New Phytol. 2007;173:181-90.

67. Lu W, Zhang F, Cao Y. Mobilization of soil phosphorus by low-molecularweight organic acids. In: Horst WJ, Schenk MK, Bürkert A, Claassen N, Flessa $H$, Frommer WB, et al., editors. Plant Nutrition: Food security and sustainability of agro-ecosystems through basic and applied research. Dordrecht: Springer Netherlands; 2001. p. 554-5. https://doi.org/10.1007/0306-47624-X_268.

68. Hunter P, Teakle G, Bending G. Root traits and microbial community interactions in relation to phosphorus availability and acquisition, with particular reference to Brassica. Front Plant Sci. 2014;5:27. https://doi.org/10. 3389/fpls.2014.00027

69. Schmidt H, Günther C, Weber M, Spörlein C, Loscher S, Böttcher C, et al. Metabolome analysis of Arabidopsis thaliana roots identifies a key metabolic pathway for iron acquisition. PLoS One. 2014;9:1-11.

70. Dotaniya ML, Meena VD. Rhizosphere effect on nutrient availability in soil and its uptake by plants: a review. Proc Natl Acad Sci India Sect B Biol Sci. 2015;85:1-12. https://doi.org/10.1007/s40011-013-0297-0.
71. Bussweiler Y, Borovinskaya O, Husted S, Persson DO, Hansen TH, Stemtan C. High-speed, high-resolution, multi-element imaging of plant root crosssections to highlight nutrient transport pathways. In: Teledyne CETAC Technologies Technical Report; 2017.

72. Strock CF. Morrow de la Riva L, Lynch JP. Reduction in root secondary growth as a strategy for phosphorus acquisition. Plant Physiol. 2018;176: 691-703. https://doi.org/10.1104/pp.17.01583.

73. Wen Z, Li H, Shen Q, Tang X, Xiong C, Li H, et al. Tradeoffs among root morphology, exudation and mycorrhizal symbioses for phosphorusacquisition strategies of 16 crop species. New Phytol. 2019;223:882-95. https://doi.org/10.1111/nph.15833.

74. Nakamura Y. Phosphate starvation and membrane lipid remodeling in seed plants. Prog Lipid Res. 2013;52:43-50. https://doi.org/10.1016/j.plipres.2012.07.002.

75. Tawaraya K, Honda S, Cheng W, Chuba M, Okazaki Y, Saito K, et al. Ancient rice cultivar extensively replaces phospholipids with non-phosphorus glycolipid under phosphorus deficiency. Physiol Plant. 2018;163:297-305. https://doi.org/10.1111/ppl.12699.

76. Siebers M, Dörmann P, Hölzl G. Membrane remodelling in phosphorusdeficient plants. In: Annual plant reviews volume 48. Hoboken: John Wiley \& Sons, Inc.; 2015. p. 237-63. https://doi.org/10.1002/9781118958841.ch9.

77. Li M, Welti R, Wang X. Quantitative profiling of Arabidopsis polar glycerolipids in response to phosphorus starvation. Roles of phospholipases $D \zeta 1$ and DZ2 in phosphatidylcholine hydrolysis and

digalactosyldiacylglycerol accumulation in phosphorus-starved plants. Plant Physiol. 2006;142:750-61. https://doi.org/10.1104/pp.106.085647.

78. Connorton JM, Balk J, Rodríguez-Celma J. Iron homeostasis in plants - a brief overview. Metallomics. 2017;9:813-23. https://doi.org/10.1039/ C7MT00136C.

79. Hirsch J, Marin E, Floriani M, Chiarenza S, Richaud P, Nussaume L, et al. Phosphate deficiency promotes modification of iron distribution in Arabidopsis plants. Biochimie. 2006;88:1767-71. https://doi.org/10.1016/j. biochi.2006.05.007.

80. Ward JT, Lahner B, Yakubova E, Salt DE, Raghothama KG. The effect of iron on the primary root elongation of Arabidopsis during phosphate deficiency. Plant Physiol. 2008;147:1181-91.

81. Baxter I. Ionomics: studying the social network of mineral nutrients. Curr Opin Plant Biol. 2009;12:381-6. https://doi.org/10.1016/j.pbi.2009.05.002.

82. Akhtar MS, Oki Y, Adachi T. Mobilization and acquisition of sparingly soluble P-sources by Brassica cultivars under P-starved environment I. differential growth response, P-efficiency characteristics and P-remobilization. J Integr Plant Biol. 2009;51:1008-23.

83. White PJ, Broadley MR. Biofortification of crops with seven mineral elements often lacking in human diets - iron, zinc, copper, calcium, magnesium, selenium and iodine. New Phytol. 2009;182:49-84. https://doi.org/10.1111/j. 1469-8137.2008.02738.x

84. Bouis HE, Saltzman A. Improving nutrition through biofortification: a review of evidence from HarvestPlus, 2003 through 2016. Glob Food Sec. 2017;12: 49-58. https://doi.org/10.1016/j.gfs.2017.01.009.

85. Thomas CL, Graham NS, Hayden R, Meacham MC, Neugebauer K, Nightingale $M$, et al. High-throughput phenotyping (HTP) identifies seedling root traits linked to variation in seed yield and nutrient capture in fieldgrown oilseed rape (Brassica napus L.). Ann Bot. 2016;118:655-65. https:// doi.org/10.1093/aob/mcw046.

86. Lu W, Wang X, Wang F. Adaptive minirhizotron for pepper roots observation and its installation based on root system architecture traits. Plant Methods. 2019;15:29. https://doi.org/10.1186/s13007-019-0414-z.

87. Kinsella RJ, Kahari A, Haider S, Zamora J, Proctor G, Spudich G, et al. Ensembl BioMarts: a hub for data retrieval across taxonomic space. Database. 2011;2011:bar030. https://doi.org/10.1093/database/bar030.

88. Wickham H. ggplot2: elegant graphics for data analysis. Cham: Springer International Publishing; 2016. https://doi.org/10.1007/978-3-319-24277-4.

89. Grzelak MM, Wróbel PM, Lankosz M, Stęgowski Z, Chmura Ł, Adamek D, et al. Diagnosis of ovarian tumour tissues by SR-FTIR spectroscopy: a pilot study. Spectrochim Acta Part A Mol Biomol Spectrosc. 2018;203:48-55. https://doi.org/10.1016/j.saa.2018.05.070

90. Dobson G, Shepherd T, Verrall SR, Conner S, McNicol JW, Ramsay G, et al. Phytochemical diversity in tubers of potato cultivars and landraces using a GS-MS metabolomics approach. J Agric Food Chem. 2008;56:10280-91. https://doi.org/10.1021/jf801370b.

91. Foito A, Byrne SL, Hackett CA, Hancock RD, Stewart D, Barth S. Short-term response in leaf metabolism of perennial ryegrass (Lolium perenne) to 
alterations in nitrogen supply. Metabolomics. 2013;9:145-56. https:/doi.org/ 10.1007/s11306-012-0435-3.

92. White PJ, Broadley MR, Thompson JA, McNicol JW, Crawley MJ, Poulton PR, et al. Testing the distinctness of shoot ionomes of angiosperm families using the Rothamsted Park grass continuous Hay experiment. New Phytol. 2012;196:101-9. https://doi.org/10.1111/j.1469-8137.2012.04228.x.

93. Schindelin J, Arganda-Carreras I, Frise E, Kaynig V, Longair M, Pietzsch T, et al. Fij: an open-source platform for biological-image analysis. Nat Methods. 2012;9:676. https://doi.org/10.1038/nmeth.2019.

94. Vogel-Mikuš K, Pongrac P, Pelicon P. Micro-PIXE elemental mapping for ionome studies of crop plants. Int J PIXE. 2014;24:217-33.

95. Pongrac P, Vogel-Mikuš K, Regvar M, Kaligarič M, Vavpetič P, Kelemen M, et al. On the distribution and evaluation of $\mathrm{Na}, \mathrm{Mg}$ and $\mathrm{Cl}$ in leaves of selected halophytes. Nucl Instruments Methods Phys Res Sect B Beam Interact Mater Atoms. 2013:306:144-9. https://doi.org/10.1016/..nimb.2012.12.057.

96. Ryan CG. Quantitative trace element imaging using PIXE and the nuclear microprobe. Int J Imaging Syst Technol. 2000;11:219-30.

97. Demšar J, Curk T, Erjavec A, Hočevar T, Milutinovič M, Možina $M$, et al. Orange: data mining toolbox in python. J Mach Learn Res. 2013;14: 23492353.

98. Toplak M, Birarda G, Read S, Sandt C, Rosendahl SM, Vaccari L, et al. Infrared Orange: connecting hyperspectral data with machine learning. Synchrotron Radiat News. 2017;30:40-5. https://doi.org/10.1080/08940886.2017.1338424.

\section{Publisher's Note}

Springer Nature remains neutral with regard to jurisdictional claims in published maps and institutional affiliations.

Ready to submit your research? Choose BMC and benefit from:

- fast, convenient online submission

- thorough peer review by experienced researchers in your field

- rapid publication on acceptance

- support for research data, including large and complex data types

- gold Open Access which fosters wider collaboration and increased citations

- maximum visibility for your research: over $100 \mathrm{M}$ website views per year

At $\mathrm{BMC}$, research is always in progress.

Learn more biomedcentral.com/submissions 